\title{
High-flux optical systems for solar thermochemistry
}

\author{
Gaël Levêque ${ }^{\mathrm{a}}$, Roman Bader ${ }^{\mathrm{b}}$, Wojciech Lipiński ${ }^{\mathrm{b}}$, Sophia Haussener ${ }^{\mathrm{a}, *}$ \\ ${ }^{a}$ Institute of Mechanical Engineering, Ecole Polytechnique Fédérale de Lausanne, 1015 Lausanne, Switzerland \\ ${ }^{\mathrm{b}}$ Research School of Engineering, The Australian National University, Canberra, ACT 2601, Australia
}

\section{A R T I C L E I N F O}

\section{Article history:}

Received 7 March 2017

Received in revised form 7 July 2017

Accepted 16 July 2017

Available online $\mathrm{xxxx}$

\section{Keywords:}

High-flux

Optics

Solar

Thermochemistry

Solar fuels

\begin{abstract}
A B S T R A C T
High-flux optical systems (HFOSs) are optical concentrators used to increase the radiative flux of the natural terrestrial solar irradiation. High radiative flux concentration leads to high energy density in solar receivers which allows to obtain high temperatures. In solar thermochemical applications, the hightemperature heat drives endothermic thermochemical reactions. HFOSs have been deployed for research and development of solar thermochemical devices and systems, from solar reacting media to solar reactors. Here, we review the designs and characteristics of HFOSs as well as challenges and opportunities in the area of high-flux optical systems for solar thermochemical applications.
\end{abstract}

(ㄷ) 2017 Elsevier Ltd. All rights reserved.

\section{Introduction and historical background}

The development of and advancement in solar concentrator technology, high-temperature solar receiver design and demonstration, and reversible redox or temperature-stable materials has opened new opportunities and routes for high-temperature solar applications. The most challenging of these solar applications are approaches which incorporate chemical reactions, and which operate at extreme conditions in terms of temperature and radiative flux (temperatures $>1000 \mathrm{~K}$ and average radiative fluxes $>100 \mathrm{~kW} / \mathrm{m}^{2}$ ). Solar thermochemistry, which refers to any endothermic chemical process that uses solar energy as the source of high-temperature heat, is the field that deals with the materials development, reaction kinetics analysis, reactor modeling and design, demonstration and scale-up of such solar-driven thermochemical reactions and processes. This field has recently picked up momentum driven by the desire for alternative, renewable and sustainable approaches for fuel processing, and material and chemical commodity production, as well as for direct, energydense, and long-term storage of solar energy. Among the existing solar-driven, non-biological chemistry routes which include solar thermochemistry, photocatalysis and photoelectrochemistry, solar thermochemistry has reached the largest scale demonstrations (up to $100 \mathrm{~kW}$ ) (Villasmil et al., 2013; Chueh et al., 2010; Säck et al., 2016), demonstrated stability over hundreds of cycles (Malonzo et al., 2014), and enormous versatility in demonstrated chemical

\footnotetext{
* Corresponding author.

E-mail address: sophia.haussener@epfl.ch (S. Haussener).
}

reactions (Scheffe and Steinfeld, 2014; Steinfeld, May 2005; Romero and Steinfeld, 2012; Bader and Lipinski, 2017).

The field of solar thermochemistry started with investigations of the direct thermolysis of water in the 70s (Fletcher and Moen, 1977). The direct thermolysis of water requires temperatures above $4000 \mathrm{~K}$ for full dissociation, and temperatures in the range of $2600-2800 \mathrm{~K}$ for at least $20 \%$ water dissociation. Furthermore, the direct thermolysis results in a high-temperature mixture of hydrogen and oxygen, which has proven difficult to efficiently and safely separate. Multi-step thermochemical water-splitting cycles have been proposed, which can by-pass the separation problem, and allow operation at reduced temperatures (Scheffe and Steinfeld, 2014; Romero and Steinfeld, 2012; Bader and Lipinski, 2017; Loutzenhiser et al., 2011; Yadav and Banerjee, 2016). These multi-step processes typically use metal-oxide redox pairs as an internal oxygen vector. An endothermic reduction step at high temperatures reduces the metal-oxide and an exothermic oxidation step oxides the reduced metal-oxide with steam and/or $\mathrm{CO}_{2}$ to produce $\mathrm{H}_{2}$ and/or $\mathrm{CO}$ and the initial metal oxide. The metal oxides used in the cycle are recycled for continuous operation. Volatile oxides (their reduced species is obtained in vapor phase and requires quenching to solidify) such as zinc/zinc-oxides require reduction temperatures above $2000 \mathrm{~K}$ (Abanades et al., 2007; Schunk et al., 2008). Non-volatile oxides remain in the solid phase throughout the cycle. This group contains mainly "engineered" materials, i.e. metal oxides which are doped with other metals in order to facilitate the reduction and/or improve the thermal stability. The first of this kind have been doped ferrites $\left(\mathrm{Fe}_{1-\mathrm{x}} \mathrm{M}_{\mathrm{x}}\right)_{3} \mathrm{O}_{4}$ with $\mathrm{M}=\mathrm{Ni}, \mathrm{Mn}, \mathrm{Co}, \mathrm{Zn}$ and others. Non-stoichiometric ceria-based and 
perovskite-type materials have shown potential in terms of fuel productivity and thermal stability (Chueh et al., 2010; Malonzo et al., 2014), and are currently more intensively researched. These oxides generally present a lower reduction temperature (around $1800 \mathrm{~K})$, but also a smaller productivity $\left(220 \mu \mathrm{mol}_{\mathrm{CO}} / \mathrm{g}\right.$ for structured pure ceria (Furler et al., 2014) than stoichiometric oxides. Perovskite-based structures, such as $\mathrm{La}_{\mathrm{x}} \mathrm{Sr}_{\mathrm{y}} \mathrm{Mn}_{\mathrm{z}} \mathrm{Al}_{\mathrm{w}} \mathrm{O}_{3}$ and $\mathrm{La}_{\mathrm{x}} \mathrm{Ca}_{\mathrm{y}}-$ $\mathrm{Mn}_{\mathrm{z}} \mathrm{Al}_{\mathrm{w}} \mathrm{O}_{3}$ based systems, have shown an order of magnitude increase in the oxygen non-stoichiometry (Cooper et al., 2015; McDaniel et al., 2013), evolving up to ten times more fuel than ceria at comparable temperatures, and therefore show great promise for future investigations. An alternative way to reduce the temperatures involved includes the utilization of cycles incorporating more than two steps. Examples are the three-step manganese cycle (Sturzenegger and Nüesch, 1999) or the three-step sulfur-iodine cycle (Kubo et al., 2004), requiring temperatures for full reaction conversion in the range of 1600 and $1400 \mathrm{~K}$, respectively. Another way to reduce the reduction temperature is by hybridizing the solar-driven process with a carbon source for carbothermal reduction. This approach has been used for the zinc/ zinc-oxide cycle and the zinc-oxide reduction temperature was decreased by almost $800 \mathrm{~K}$ (Osinga et al., 2004; Tzouganatos et al., 2016). Hybrid of solar-fossil or solar-carbon processes (where the carbon can come from biomass or recycled fossil resources) are an alternative solar thermochemical pathway specifically aiming at hydrogen and synthesis gas production. Effectively, the carbonaceous resources are upgraded by solar energy to gases with higher energy content. In these processes the carbonaceous feedstock is used purely as the chemical source of hydrogen and carbon (Piatkowski et al., 2011). Solar steam- or dry-gasification operates at temperatures of $1200 \mathrm{~K}$ (Piatkowski et al., 2011), solar thermal cracking and reforming in the range of 1300-1600 K (even lower temperatures achievable for pressures below 1 bar) (Dahl et al., 2004; Maag et al., 2009; Agrafiotis et al., 2014). Hybridization of solar thermochemistry with electrochemical reactions has also been proposed as a way to reduce the required temperatures and electrical input power into the systems (Licht, 2009). Temperatures above $700-1000 \mathrm{~K}$ can lead to a reduction in electrical potential of more than $20 \%$ (for example for water and carbon dioxide reduction) while ensuring large enough electrical conductivity in the solid oxide electrolyte component of the system. Finally, concentrated solar energy has been used to drive a variety of other thermochemical reactions (Bader and Lipinski, 2017), including the processing of materials and chemical commodities such as calcination of limestone to lime at temperatures of around $1200 \mathrm{~K}$ (Meier et al., 2006), near-vacuum carbothermal reduction of alumina to aluminum in the temperature range of 1300-2000 K (Halmann et al., 2007), and ammonia production via alumina/aluminum nitride cycling at a temperature of $2000 \mathrm{~K}$ (Gálvez et al., 2007).

All these thermochemical processes stand in contrast to processes where the high temperature heat is used as industrial process heat, for example for: food sterilization or drying (in the temperature range of $330-430 \mathrm{~K}$ ), or plastic, paper, textile or timber processing (in the temperature range of $330-450 \mathrm{~K}$ ), or heating and superheating of heat transfer fluids for power production (in the temperature range of 700-1400 K). Solar thermochemistry also stands in contrast to approaches where the photons and the resulting separated electrons and holes are used in photocatalytic or photoelectrochemical approaches (for example for water purification, or water and carbon dioxide reduction) generally operating at temperatures below $350 \mathrm{~K}$ (McKone et al., 2013). These processes are also explored at higher temperatures and under irradiation concentration (Dumortier et al., 2015; Tembhurne and Haussener, 2016a, 2016b) but charge separation is usually not effective at temperatures above $370 \mathrm{~K}$. Both of these approaches
- solar thermal and photo-driven - do not rely on thermochemistry and are not considered in this review.

Obviously, solar irradiation, with its low energy density in the range of $300-1000 \mathrm{~W} / \mathrm{m}^{2}$ (dependent on location, season and time during the day), needs to be concentrated in order to provide energy densities able to produce heat at temperatures above $1000 \mathrm{~K}$. Optical concentration of solar radiation allows for reaching such high temperatures. In the following, we focus on High-Flux Optical Systems (HFOSs) which can provide temperatures above $1000 \mathrm{~K}$ and therefore are relevant for research and development in solar thermochemistry. These HFOSs provide concentration ratios in the range of $100-10,000$, resulting in highly concentrated fluxes in the range of $100-10,000 \mathrm{~kW} / \mathrm{m}^{2}$ (for a $1 \mathrm{~kW} / \mathrm{m}^{2}$ irradiation). Such concentrations and also rapid heating rates can be delivered by point focusing technology, but not easily by any electric or fossil fuel driven setup.

The development and implementation of HFOSs followed the activities in the concentrating solar power and solar thermochemistry community (Yadav and Banerjee, 2016). The first major setup was commissioned in 1970 in Odeillo, France. This solar furnace provided up to $1 \mathrm{MW}$ of concentrated solar radiation, with concentration ratios up to 10,000 for research applications (Trombe and Vinh, 1973). A similar solar furnace was build a little later in Uzbekistan (1 MW solar radiative power) (Unique objects and collections of Uzbekistan Academy of Sciences). These research facilities were followed by a solar tower facility of $\sim 6.8 \mathrm{MW}$ in 1983 in France. This tower however was only used for investigations on solar power application. In the early 90s, Sandia National Laboratories followed with a solar furnace $(16 \mathrm{~kW})$, and the Plataforma Solar de Almeria with a solar tower ( 2.7 MW). These developments coincided with the oil crises in 1973 and 1979, but slowed with the recovery of the oil price in the 90s. Facilities in Israel (solar tower of $650 \mathrm{~kW}$ at the Weizmann Institute, 1988), in the US (solar furnace of $10 \mathrm{~kW}$ at the National Renewable Energy Laboratory, 1994), in Germany (solar furnace of $25 \mathrm{~kW}$ at the Deutsche Zentrum für Raum- und Lufthfahrt, 1996), and in Switzerland (solar furnace of $40 \mathrm{~kW}$ at the Paul Scherrer Institut, 1999) followed. Since the 90s, a revival of solar thermal and thermochemical research has pushed high-flux application and solar thermochemistry back into the spotlight, with a steadily increasing number of publications on the subject (Yadav and Banerjee, 2016). As a result, HFOS have been implemented by various research groups, each considering its own needs and limitations. Thus, a variety in geometry, size, power, etc. exists, most being thoroughly described in the literature.

A major milestone has been the development of in-house solar simulators, which provide a wider accessibility of HFOSs. The first high-flux solar simulator was built at the Lawrence Berkeley National Laboratory in 1991, exhibiting a power of $3 \mathrm{~kW}$ and a peak flux up to $16 \mathrm{MW} / \mathrm{m}^{2}$ (Kuhn and Hunt, 1991). Solar simulators mimic radiative characteristics of typical point focusing solar concentrators, alleviate the constraints for installation (e.g. local solar resource or large infrastructures), and allow for testing under stable, controlled and reproducible laboratory and flux conditions. This marks a significant advantage for research and development compared to on-sun facilities which provide transient and not well predictable conditions. However they do not eliminate the need for experimental data collected in real sun conditions, which capture the transients at various-time scales to which the receiver and materials are exposed. A simulator at ETH Zürich (6.7 kW and peak flux of $4.3 \mathrm{MW} / \mathrm{m}^{2}$ ) followed in 2003 (Hirsch et al., 2003), based on an elliptical reflector and an Ar-arc bulb. The simulators at the Paul Scherrer Institute and the ETH Zürich following in 2007 (Petrasch et al., 2007) marked the beginning of the development and implementation of a whole array of simulators based on multiple ellipsoidal reflector units (usually 7-10 units) with Xe-arc bulbs 
(Krueger et al., 2013; Sarwar et al., 2014; Ekman et al., 2015; Dong et al., 2015; Gill et al., 2015). Recently, the trend has shifted to simulators composed of a larger number of smaller power units allowing for a larger versatility in power and flux distribution in the focus, such as the simulators at EPFL and ANU with 18 units of $2.5 \mathrm{~kW}_{\mathrm{el}}$ (Levêque et al., 2016), or the similar at the Niigata University with 19 units of $7 \mathrm{~kW}_{\mathrm{el}}$ (Kodama et al., 2015). These developments further coincide with installation of demonstration plants and commercial plants for solar power production based on solar tower and dish technologies, cumulating in an installed capacity of several GW (Li et al., 2016; CSP World, NREL, Téllez et al., 2014). These technologies allow for concentrations and temperatures relevant for solar thermochemistry and, therefore, can be seen as a first step towards large-scale implementation and demonstration of solar thermochemistry.

Here, we will review the status of HFOSs for solar thermochemistry applications, describe the design principles and limitations, compare the various on-sun and indoor installations, and review engineering challenges associated with the development and implementation.

\section{Concentrating solar energy - theoretical background}

\subsection{Definitions}

A solar concentrator is placed between the incident solar radiation and a solar receiver, which will absorb the concentrated radiation and convert it to high temperature heat to be used in subsequent processing steps (such as the thermochemical processes). The sun can be approximated as a black body at a temperature of about $5777 \mathrm{~K}$. The spectral characteristics of the solar irradiation arriving at the earth orbit can therefore be approximated by the emissive power of a blackbody at said temperature. The direct solar light is reaching the earth as almost collimated rays (cone half-angle, $\theta_{\mathrm{s}}$, of about $4.65 \mathrm{mrad}$ due to the sun's shape and distance between the earth and sun). Once the radiation travels through the atmosphere, it will be absorbed and scattered by molecules, aerosols, and dust in the various layers. The resulting reduction in the spectral incident flux and the reduction in the collimated (direct radiation) part of the solar irradiation depends on the local atmosphere and consequently the weather conditions. Concentration requires redirecting these rays into a common position, which can be a surface, a line (line-focusing systems), or a point (point-focusing systems) (Goswami et al., 2000). Examples for line-focusing systems are parabolic trough or linear Fresnel concentrations, and examples for point-focusing systems are solar tower systems and solar dishes. The latter achieve significantly higher concentration ratios than the former.

Because concentration is obtained through specular reflections of rays, only the direct part of the solar irradiation can be concentrated, while the diffuse part is lost. For locations like Southern Spain or Southern California, the direct fraction of the irradiation is above $80 \%$ throughout the year, while it can drop below $60 \%$ for locations with high overall magnitude but high aerosol/soot pollution in the atmosphere, such as for example in Eastern China. A normalized, benchmarking spectrum often used in the community is the Air Mass 1.5D spectrum (AM1.5D), which represents the spectrum resulting from solar energy traveling through the atmosphere with a path length 1.5 times the shortest possible path length (if the sun is directly overhead) and normalized to a magnitude of $900 \mathrm{~W} / \mathrm{m}^{2}$, including only the direct irradiation (Gueymard, 2004; Gueymard et al., 2002). The instantaneous, area-averaged flux concentration ratio is defined based on the incident energy flux (the direct normal irradiance is considered only) and the flux arriving at the receiver's aperture with a given aperture area (which can vary in time, spectrum, and over the aperture area),

$C=\frac{\dot{Q}_{\mathrm{rec}}}{D N I \cdot A_{\mathrm{rec}}}$.

Sometimes the geometrical concentration ratio is defined (Malonzo et al., 2014), which correspond to the ratio between the collector area and the receiver area. However, this definition assumes a perfect energy conversion efficiency during the redirection and concentration steps.

The theoretical maximum concentrations are given by the second law of thermodynamics, and are limited by $\theta_{\text {sun }}$, specifically the inverse of the sinus of $\theta_{\text {sun }}$ for line-focusing concentrators, i.e. $C_{\max }=215$, and the inverse of the square of the sinus of $\theta_{\mathrm{s}}$ for point-focusing concentrators, i.e. $C_{\max }=46,248$.

In order to assess what concentration ratios are required to theoretically achieve a temperature above $1000 \mathrm{~K}$, the stagnation temperature, $T_{\text {stag, }}$, of an absorbing surface (with absorptivity, $\alpha$, and emissivity, $\varepsilon$ ) at radiative equilibrium, i.e. when the absorbed flux equals the flux emitted by the surface,

$\dot{\mathrm{Q}}_{\mathrm{abs}}=\alpha C \cdot D N I=\dot{\mathrm{Q}}_{\mathrm{emit}}=\varepsilon \sigma T_{\mathrm{stag}}^{4}$,

can be calculated. The stagnation temperature scales with the fourth root of the received power, due to the temperatureinduced radiative losses. For a perfect blackbody absorber (i.e. $\alpha=\varepsilon=1$ ), a stagnation temperature of $1000 \mathrm{~K}$ requires a concentration ratio of $57-63$ for a DNI of $900-1000 \mathrm{~W} / \mathrm{m}^{2}$. However, this temperature is impractical because no power is available for further conversion. Instead, we consider the absorption efficiency of the receiver, defined as the ratio between the net energy available to the receiver (i.e. difference between absorbed and emitted energy) at a given temperature and the incoming radiation,

$\eta_{\mathrm{abs}}=\frac{\alpha C \cdot D N I-\varepsilon \sigma T_{\mathrm{abs}}^{4}}{\dot{q}_{\mathrm{in}}}=1-\frac{\sigma T_{\mathrm{abs}}^{4}}{D N I \cdot C}$,

for $\alpha=\varepsilon=1$. This relation is displayed for various $C$ in Fig. 1. A highly concentrated source of light allows for high absorption efficiencies, thus most of the collected light is efficiently converted as heat for further processes. Such efficiencies are difficult to achieve with conventional means and thus render the use of HFOSs for driving highly endothermic reactions potentially viable and interesting. For example with concentrations above 1000 , it is theoretically possible to

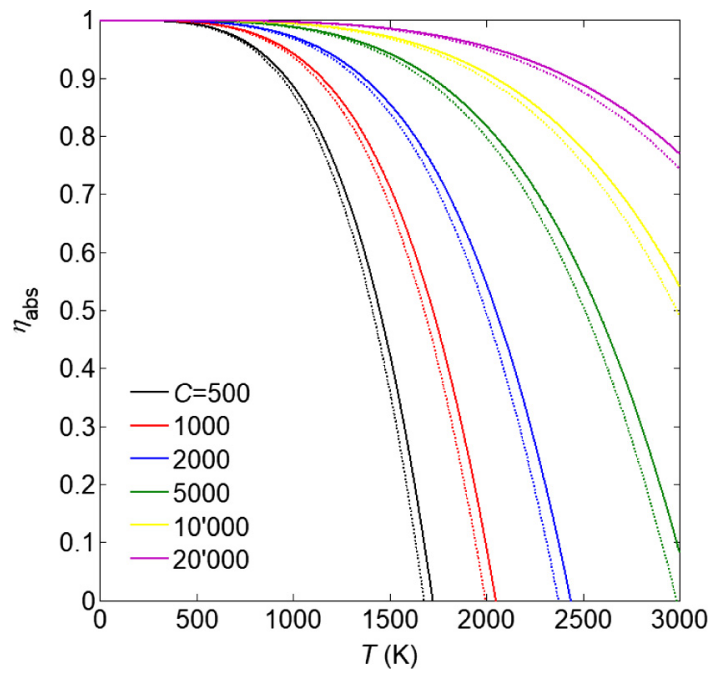

Fig. 1. Absorption efficiency of a perfectly insulated blackbody receiver as a function of temperature and concentration ratio for DNI of $1000 \mathrm{~W} / \mathrm{m}^{2}$ (solid lines) and $900 \mathrm{~W} / \mathrm{m}^{2}$ (dashed lines) 
transfer more than $90 \%$ of the harvested radiation to a reactor operating at $1000 \mathrm{~K}$. Such high concentration ratios can only be obtained by point-focusing technologies, thus only these technologies and approaches will be further described below.

Following the exergetic analysis of solar thermal receivers (Petela et al., 2010), the exergy efficiency is given by the ratio of exergy of the absorbed heat and the exergy of the emitted solar radiation,

$\varepsilon_{\mathrm{abs}}=\frac{\eta_{\text {Carnot }} \dot{q}_{\mathrm{abs}}}{D N I \cdot C \cdot \varphi_{\mathrm{en}-\mathrm{ex}}}$,

where the energy-to-exergy efficiency, $\varphi_{\text {ex-en, approaches } 1 \text { if the }}$ radiation source temperature approaches infinity. Eq. (4) then reduces to

$\varepsilon_{\mathrm{abs}, \mathrm{i}}=\eta_{\text {Carnot }} \eta_{\mathrm{abs}}$

which is consistent with an ideal efficiency often defined in this community (Steinfeld, 2005; Romero and Steinfeld, 2012; Bader and Lipinski, 2017; Li et al., 2016), given as the product of the Carnot efficiency and the absorber efficiency. Utilizing Eq. (5), an optimal temperature can be defined at which $\varepsilon_{\mathrm{abs}, \mathrm{i}}$ is maximized (i.e. $d \varepsilon_{\mathrm{abs}, \mathrm{i}}\left(d T_{\mathrm{abs}}=0\right)$ ). For temperatures of $1000 \mathrm{~K}$ or higher, the optimal temperature corresponds to $C$ of 586 and 651 or higher (for DNI equals $1000 \mathrm{~W} / \mathrm{m}^{2}$ and $900 \mathrm{~W} / \mathrm{m}^{2}$, respectively, and ambient temperature of $300 \mathrm{~K}$ ). For these conditions, $\varepsilon_{\mathrm{abs}, \mathrm{i}}$ is above $=0.63$ and $\eta_{\text {abs }}$ is above $=0.90$.

For the optical efficiency of a HFOS, we follow the definition given in Li et al. (2016), which describes the overall optical efficiency as the ratio of the radiative energy intercepted by the receiver with an aperture area to the maximum possible energy that can be intercepted by the total concentrator area, $A_{\text {conc }}$, for a given time period

$\eta_{\mathrm{opt}}=\frac{\int \dot{\mathrm{Q}}_{\mathrm{rec}} d t}{\int D N I \cdot A_{\mathrm{conc}} d t}$

For an accurate determination of the concentration ratio and the optical efficiency (Eqs. (1) and (6)), $\dot{Q}_{\text {rec }}$ needs to be determined. This requires either detailed measurements of the flux distribution in the receiver aperture, or an estimation or modeling of the radiative energy flux from the point of incidence, following the various redirection and concentration steps before arriving at the receiver aperture (as outlined below). The radiative intensity incident on a reflecting surface is diffusely or specularly reflected, dependent on the surface characteristics of the reflecting surface. Diffuse reflection describes reflection with non-preferential directionality. Diffuse reflection is not desired in a concentrating device and usually results from low quality surfaces or microscopic variability in the surface (surface roughness, surface impurities, microscopic surface damages and bending). Specular reflection is described by a reflectivity with preferred directionality according to the bi-directional, spectral reflectivity (Modest, 2013),

$\rho_{\lambda}^{\prime \prime}=\left\{\begin{array}{l}\infty, \text { for } \theta_{\mathrm{r}}=\theta_{\mathrm{i}} \text { and } \psi_{\mathrm{r}}=\psi_{\mathrm{i}}+\pi \\ 0, \text { for all others }\end{array}\right.$

Real surfaces often reflect according to a combination between specular and diffuse reflection. It should be emphasized that the reflectivity is not only a function of irradiation direction, wavelength, and location, but also a function of temperature.

If the travel path of a photon during the redirection and conversion in the HFOS is larger than the extinction length in the atmosphere, the photon will be absorbed or scattered, and consequently be lost. Atmospheric models need to be used for an estimation of the radiative properties of the atmosphere (Goody and Yung, 1989), and the radiative transfer equation needs to be solved for a detailed estimate of the decrease in the radiative intensity along the path (Modest, 2013; Siegel, 1971).

\subsection{Optics for flux concentration}

Optical concentrators collect solar irradiation from a large area, and transfer and concentrate it to a smaller surface, thus increasing the density of the irradiation. Different approaches are used to reach this goal, depending on the source of light (natural or synthetic), on the power and temperature desired, and on other practical criteria that will be discussed below. Three main types of optical concentrators are defined: (i) solar concentrators, which concentrate quasi-collimated light sources e.g. solar light; (ii) solar simulators, concentrating point-emitting light sources such as that emitted by a lamp; and (iii) secondary concentrators, meant to further concentrate already convergent light sources.

\subsubsection{Solar concentrator}

Basic geometry - Concentration is obtained by altering the direction of nearly collimated light rays by means of reflection at the expense of a loss in transmitted energy. This loss comes from the intrinsic optical quality of the materials (reflectance is never equal to 1 ), surface quality, or impurities which alter the path of rays. The number of reflections should thus be minimized to limit these losses. The solar light source irradiates the earth with an angle and declination that varies throughout hours and days, so highflux solar concentrators need to track the sun throughout the day. The simplest solar concentrator arrangement consists of a solar-tracking dish, which allows for both concentration and tracking of the sun with only one reflection, the thermochemical reactor being placed at the focus of the parabolic concentrator. For practicality, it is generally preferred to have a fixed placement of the reactor, which simplifies operation. Hence, the most common arrangement, referred to as solar furnace, features a flat heliostat (or an array thereof), which are commercially available with sun tracking capability, and a parabolic concentrator, i.e. a paraboloid of revolution. Indeed, by its very definition a parabola will concentrate a collimated ray to its focus, it is thus the most widely used concentrator shape. Its profile is described by

$y=\frac{x^{2}}{4 f}$,

for a "cut" of a paraboloid of revolution extending towards $y>0$. A parabola can be described as the loci of points equidistant from its focal point and its directrix (Fig. 2). As a result, every $d l$ is locally a mediatrix between the vertical direction and the focal point direction, which implies a specular reflection along this direction. A parabola can be defined by its focal length, $f$, and diameter, $d$, which condition the rim angle obtained (Fig. 2). A concentrator is more often designed starting by the required rim angle $\theta_{\text {rim }}$, which conditions its use and concentration ratio, and the power at the focal plane, which conditions its diameter. The ratio between focal distance and diameter of the concentrator is dependent on the chosen rim angle and given by

$f / d=\frac{1}{4 \tan \left(\theta_{\text {rim }} / 2\right)}$.

Since the sun rays are not perfectly collimated $\left(\theta_{\text {sun }}>0\right)$, the image at the focus of the concentrating parabola will not be a perfect point but a spot, whose size depends on the focal length. As a result, the reachable concentration depends on the parameters chosen for the parabola (Bliss, 1957)

$C_{\max } \approx \frac{1}{\theta_{\text {sun }}^{2}} \sin ^{2} \theta_{\text {rim }}$ 
a)

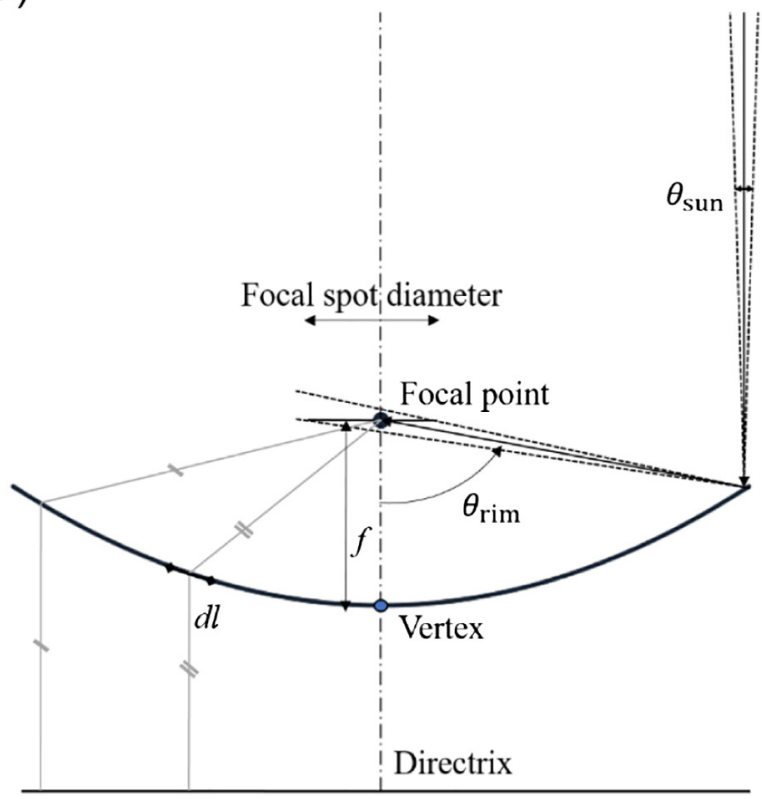

b)

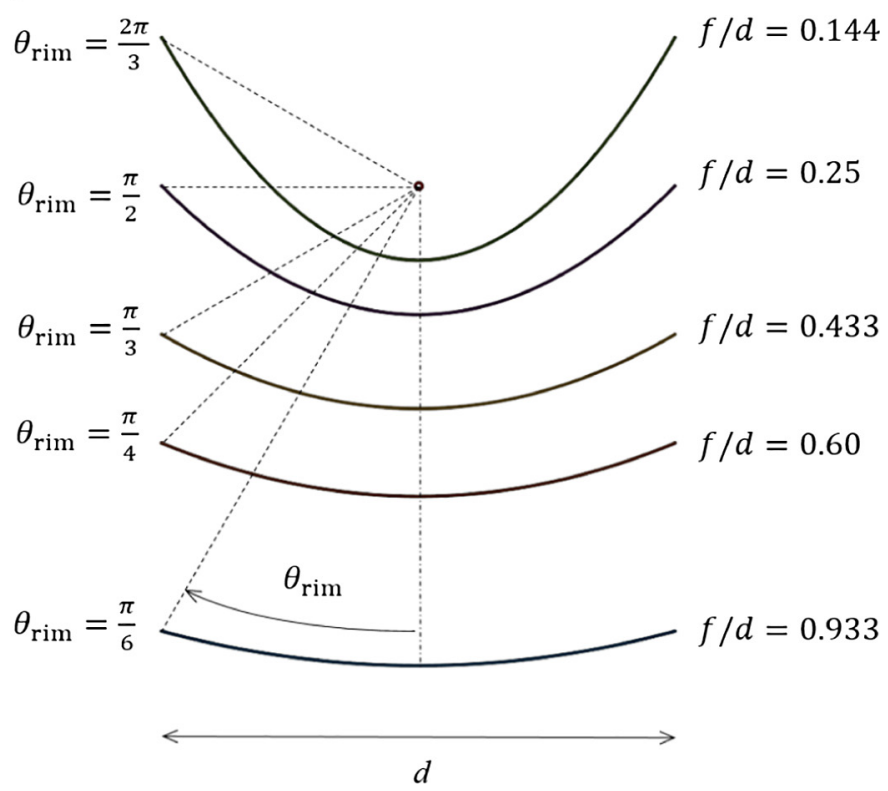

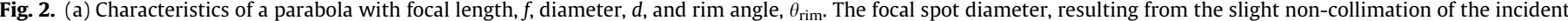
solar rays $\left(\theta_{\text {sun }}>0\right)$, is indicated. (b) Conditioning of the rim angle as a result of the varying focal length for a given diameter (Siegel, 1971 ).

$C_{\text {max }}$ varies between $\sim 10,000$ (for $\theta_{\text {rim }}=\pi / 6$ ) to $\sim 45,000$ (for $\theta_{\text {rim }}=-$ $\pi / 2$ ). Note that Eq. (10) only expresses $C$ within the "hot spot", i.e. the brightest spot at the center of the focus, and does not represent the average $C$ achieved by the concentrator. For a rim angle of $\pi / 4$, the maximum attainable concentration is 23,000 .

Approximated mirror shapes - Manufacturing a continuous parabolic mirror of large dimensions, high reflectance, and high optical surface quality is not a common and simple task. An industrial production has existed before the 1950s as a part of the war industry, the parabolas being used for antiaircraft projectors. A few of them have been obtained and reused as solar concentrators for research and development (for example the MSSF at Odeillo, see Table 2). However, no such high-quality reflectors are available off-theshelves. Instead, many designs favor a faceted concentrator design (called discrete reflector). The overall shape is discretized with curved or planar facets, which can be readily manufactured (Burgess et al., 2008). As a result, though, the concentration factors are smaller than the same-size counterparts made of a one-piece parabola. If necessary, further enhancement of the concentration can be attained by using a secondary concentrator.

Practical considerations - Practicality is another important factor that has to be considered when designing an HFOS. In particular, the positioning of the reactor is of importance, and may be a design constraint for the rest of the optical design. Indeed, receivers and thermochemical reactors generally come with insulation, fluids and/or solids inlet, and instrumentation to monitor the products. This is a major reason as to why the two-reflections solar furnace arrangement is generally preferred. Another direct effect of the size of an experiment is its blockage of the light source, which can be hard to effectively assess. To counter this, the reflector can be displaced so as the light is concentrated away from the illumination axis, leading to the off-axis designs. The gain in practicality nevertheless leads to a loss of symmetry in the concentrator shape and, thus, in the flux distribution, that can render the operation of cavity reactors difficult. Moreover, a solar tower arrangement of the optical concentrator requires that all the equipment be installed at the top of the tower. It is possible to instead redirect the flux toward the floor, by introducing another reflection, in the case of the beam-down reflector design. More generally, illumination of a reactor from the top can be necessary when gravity plays a role (e.g. reaction at the top of a fluidized bed) and has led to vertical designs for small scale optical concentrators. Fig. 3 gives an overview of different point-focusing solar concentrating systems. Table 1 summarizes the main characteristics of existing solar concentrating facilities.

\subsubsection{Solar simulators}

Basic geometry - The main optical difference between a concentrator and a simulator is the geometry of the source of light. The sources that are used for solar simulators provide a quasi-pointsource of light, by means of a bulb with a high-pressure plasma. Thus, reflectors of solar simulators must collect light emitted in every direction and redirect it toward a single point. This is obtained by using an ellipsoid of revolution, described by equations

$\left(\frac{x}{a}\right)^{2}+\left(\frac{y}{b}\right)^{2}=1, a<b$

$2 c=2 \sqrt{a^{2}-b^{2}}$,

where $a$ and $b$ are the major and minor axes, respectively, and $2 c$ the distance between the two foci. Such a shape is drawn as the locus of all points for which the sum of the distances to the two foci is the same. As a result, the tangent on any point of the ellipse is normal to the bisector of the straights linking this point to the two foci, which implies a specular reflection along this path. By extension, a ray emitted in any direction from one of the foci will be reflected to the second. Designing a solar simulator requires to take into account the geometry and emission behavior of the bulb early, as the cathode and anode limit emission directions to be intercepted by the ellipsoidal reflector. An example is given in Fig. 4. For a given bulb emission angle and focal distance, the rim angle at the focal plane and the reflector length and width depends on the axis values (here $b_{1}=1$ and $b_{2}=2$ ). 


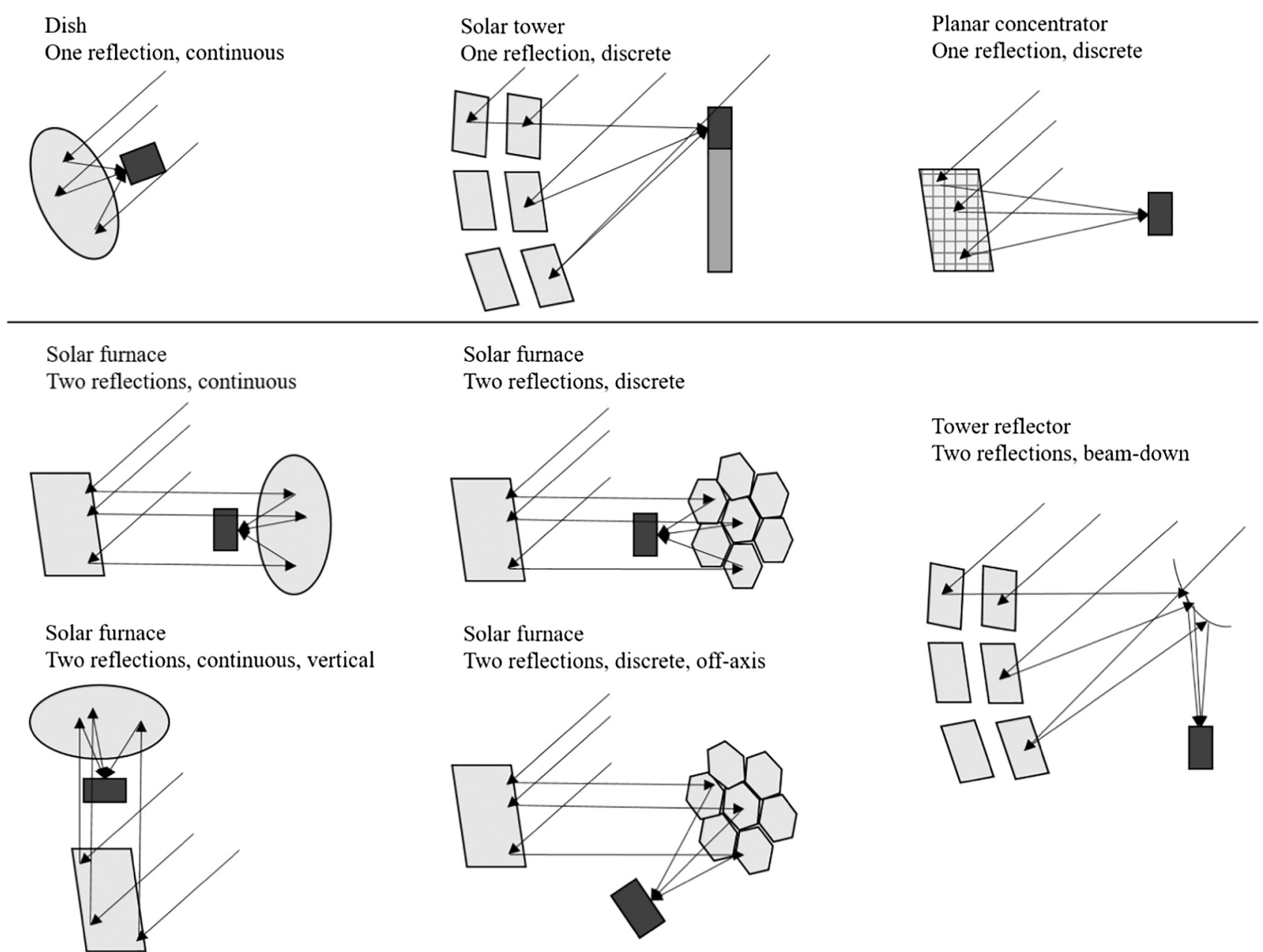

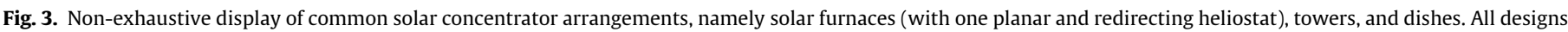

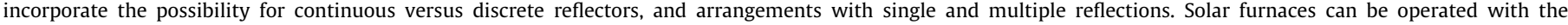
concentrated irradiation arriving in a vertical or horizontal manner, with the potential for off-axis arrangements.

Ellipsoidal reflectors are usually custom-made, via spin-forming or electroforming, with significant effect on the reflector quality and optical performance of the system (Yabe et al., 2008). The base material is coated with a reflective aluminum layer and a protective quartz layer.

Multiplication of sources -Individual lamp power is generally limited to a few $\mathrm{kW}$. Higher power requires multiplying the number of sources. The total rim angle of the final array depends thus on the number of radiation modules, and on the parameters chosen for the reflectors. Such discretization of the light source leads inevitably to a poor reproduction of a real solar continuous concentrator, notably through the existence of hotspots on planes behind the focal plane (i.e. potentially on a cavity's wall). This can logically be limited by discretizing further the source, i.e. using more lamps with reduced power and compact reflectors (Bader et al., 2014a). This approach follows the approach of faceting mirrors for solar concentrators.

Spectrum of light source - To reproduce as closely as possible the spectrum of actual solar light, three main arc-lamp light sources have been used in high-flux solar simulators: xenon (Xe), argon $(\mathrm{Ar})$, and metal halide $(\mathrm{MH})$. All have the same working principle: the lamps contain two electrodes between which an electron current is applied that ionizes the pressurized gas contained inside the quartz lamp bulb. Light is emitted as a result of the discharge of the ionized gas. None of the lamps provide a perfect match with the solar spectrum (Fig. 5). As shown below (Table 3), Xe arc-lamps are by far the most frequently used ones, followed by MH lamps. Ar lamps have not been used since 2003 and are therefore not further discussed here. MH lamps most closely follow the AM1.5D reference solar spectrum. High peaks in the Xe emission spectrum between $850 \mathrm{~nm}$ and $1 \mu \mathrm{m}$ create a significant discrepancy to the reference solar spectrum. On the other hand, unavoidable oscillations exist in the light intensity, with recorded values up to $60 \%$ of the peak intensity for $\mathrm{MH}$ lamps compared to only $9 \%$ for $\mathrm{Xe}$ lamps, with a frequency depending on the power supply $(100 \mathrm{~Hz}$ for MH lamps and $300 \mathrm{~Hz}$ for Xe lamps (Dong et al., 2015). Based on these experimental values, Xe lamps provide a more stable radiation output.

\subsubsection{Secondary concentration}

Very high concentrations can be difficult to achieve with a single concentration step. Secondary non-imaging concentrators are often considered to further increase the flux density. Non-imaging concentrators are particular in that they allow increasing the concentration at the expense of its spatial "cohesion" as it is not converging anymore. A commonly used concentrator shape is known as the compound parabolic concentrator (CPC), which is obtained by the revolution of a truncated tilted parabola (Fig. 6) (Welford, 2012). Its equation is given by 
Table 1

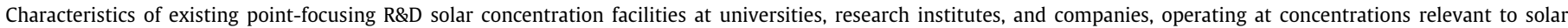
thermochemistry.

\begin{tabular}{|c|c|c|c|c|c|c|c|c|c|}
\hline Name, Location & $\begin{array}{l}\text { First } \\
\text { reference/ } \\
\text { Inauguration }\end{array}$ & Technology & $\begin{array}{l}\text { Reflection } \\
\text { stages }\end{array}$ & $\begin{array}{l}\text { Number } \\
\text { of } \\
\text { mirrors }\end{array}$ & $\begin{array}{l}\text { Total size } \\
\text { of } \\
\text { collectors }\end{array}$ & $\begin{array}{l}\text { Reflector } \\
\text { shape }\end{array}$ & $\begin{array}{l}\text { Peak } \\
\text { concentration }\end{array}$ & $\begin{array}{l}\text { Radiative } \\
\text { power } \\
(\mathrm{kW})\end{array}$ & Source \\
\hline CSIRO, Australia & 2006 & Solar tower & 1 & 450 & $800 \mathrm{~m}^{2}$ & - & - & $504^{\mathrm{e}}$ & Bader and Lipinski (2017) \\
\hline ANU, Australia & 2008 & Dish & 1 & 1 & $500 \mathrm{~m}^{2}$ & $\begin{array}{l}\text { Parabolic, } \\
\text { discrete }\end{array}$ & 14,000 & $315^{\mathrm{e}}$ & $\begin{array}{l}\text { Lovegrove et al. (2011); Pye } \\
\text { et al. (2017) }\end{array}$ \\
\hline CAS, China & 2012 & Solar tower & 1 & 100 & $10,000 \mathrm{~m}^{2}$ & - & - & $6300^{e}$ & CPS World, NREL \\
\hline $\begin{array}{l}\text { Pentakomo, Cyprus Institute, } \\
\text { Cyprus }\end{array}$ & 2015 & Solar tower & 1 & 50 & $225 \mathrm{~m}^{2}$ & - & - & $142^{\mathrm{e}}$ & $\begin{array}{l}\text { CPS World, NREL, Téllez et al. } \\
\text { (2014) }\end{array}$ \\
\hline Themis, PROMES-CNRS, France & 1983 & Solar tower & 1 & 201 & $10,794 \mathrm{~m}^{2}$ & - & $>3600$ & $6800^{e}$ & $\begin{array}{l}\text { CPS World, NREL, Téllez et al. } \\
\text { (2014) }\end{array}$ \\
\hline Eurodish, PROMES-CNRS, France & 2004 & Dish & 1 & 1 & $57 \mathrm{~m}^{2}$ & $\begin{array}{l}\text { Parabolic, } \\
\text { discrete }\end{array}$ & $9600^{f}$ & 10 & $\begin{array}{l}\text { CPS World, NREL, Téllez et al. } \\
\text { (2014) }\end{array}$ \\
\hline Jülich tower, DLR, Germany & 2008 & Solar tower & 1 & 2153 & $17,655 \mathrm{~m}^{2}$ & - & $>1000$ & $7500^{d}$ & DLR \\
\hline $\begin{array}{l}\text { Daegu tower, Daesung Energy, } \\
\text { South Korea }\end{array}$ & 2011 & Solar tower & 1 & 450 & $1800 \mathrm{~m}^{2}$ & - & - & 200 & $\begin{array}{l}\text { CPS World, NREL, Téllez et al. } \\
\text { (2014) }\end{array}$ \\
\hline CESA-1, PSA-CIEMAT, Spain & 1983 & Solar tower & 1 & 300 & $11,880 \mathrm{~m}^{2}$ & - & 3300 & 7000 & $\begin{array}{l}\text { CPS World, NREL, Téllez et al. } \\
\text { (2014) }\end{array}$ \\
\hline Eureka, Abengoa, Spain & 2010 & Solar tower & 1 & 35 & $4200 \mathrm{~m}^{2}$ & - & - & 2000 & $\begin{array}{l}\text { CPS World, NREL, Téllez et al. } \\
\text { (2014) }\end{array}$ \\
\hline Solugas, Abengoa, Spain & 2013 & Solar tower & 1 & 69 & $8349 \mathrm{~m}^{2}$ & - & - & $5260^{\mathrm{e}}$ & $\begin{array}{l}\text { CPS World, NREL, Téllez et al. } \\
\text { (2014) }\end{array}$ \\
\hline Aora Tulip, Aora, Spain & 2012 & Solar tower & 1 & 52 & $832 \mathrm{~m}^{2}$ & - & - & $524^{e}$ & $\begin{array}{l}\text { CPS World, NREL, Téllez et al. } \\
\text { (2014) }\end{array}$ \\
\hline CTAER, CTAER, Spain & 2012 & Solar tower & 1 & 13 & $1560 \mathrm{~m}^{2}$ & - & - & 8000 & $\begin{array}{l}\text { CPS World, NREL, Téllez et al. } \\
\text { (2014) }\end{array}$ \\
\hline Distal I, PSA-CIEMAT, Spain & 1992 & Dish & 1 & 1 & $44 \mathrm{~m}^{2}$ & $\begin{array}{l}\text { Parabolic, } \\
\text { discrete }\end{array}$ & $12,000^{\mathrm{f}}$ & 40 & $\begin{array}{l}\text { CPS World, NREL, Téllez et al. } \\
\text { (2014) }\end{array}$ \\
\hline Distal II, PSA-CIEMAT, Spain & 2003 & $\begin{array}{l}\text { Dish }(3 \\
\text { pieces })\end{array}$ & 1 & 1 & $57 \mathrm{~m}^{2}$ & $\begin{array}{l}\text { Parabolic, } \\
\text { discrete }\end{array}$ & $9600^{f}$ & 50 & $\begin{array}{l}\text { CPS World, NREL, Téllez et al. } \\
\text { (2014) }\end{array}$ \\
\hline CRTF, Sandia, USA & 1979 & Solar tower & 1 & 218 & $8066 \mathrm{~m}^{2}$ & - & 3500 & 6000 & Sandia National Lab \\
\hline NSTTF, Sandia, USA & 2005 & $\begin{array}{l}\text { Dish }(6 \\
\left.\text { pieces }^{\mathrm{c}}\right)\end{array}$ & 1 & 1 & $>17 \mathrm{~m}^{2 \mathrm{a}}$ & $\begin{array}{l}\text { Parabolic, } \\
\text { discrete }\end{array}$ & - & $7.5^{\mathrm{d}}$ & $\begin{array}{l}\text { CPS World, NREL, Téllez et al. } \\
\text { (2014) }\end{array}$ \\
\hline NSTTF, Sandia, USA & 1979 & $\begin{array}{l}\text { Dish }(10 \\
\left.\text { pieces }^{b}\right)\end{array}$ & 1 & 1 & $>100 \mathrm{~m}^{2 \mathrm{a}}$ & $\begin{array}{l}\text { Parabolic, } \\
\text { discrete }\end{array}$ & 15,000 & 75 & Sandia National Lab \\
\hline
\end{tabular}

${ }^{\text {a }}$ Based on diameter.

b Stirling Energy Systems dish.

c Infinia dish.

d Based on electrical power output with $20 \%$ efficiency.

e Based on collector size, averaged daily irradiation of $\sim 700 \mathrm{~W} / \mathrm{m}^{2}$, and 0.9 reflectivity.

f Assuming peak is $4 \times$ averaged concentration.

a)

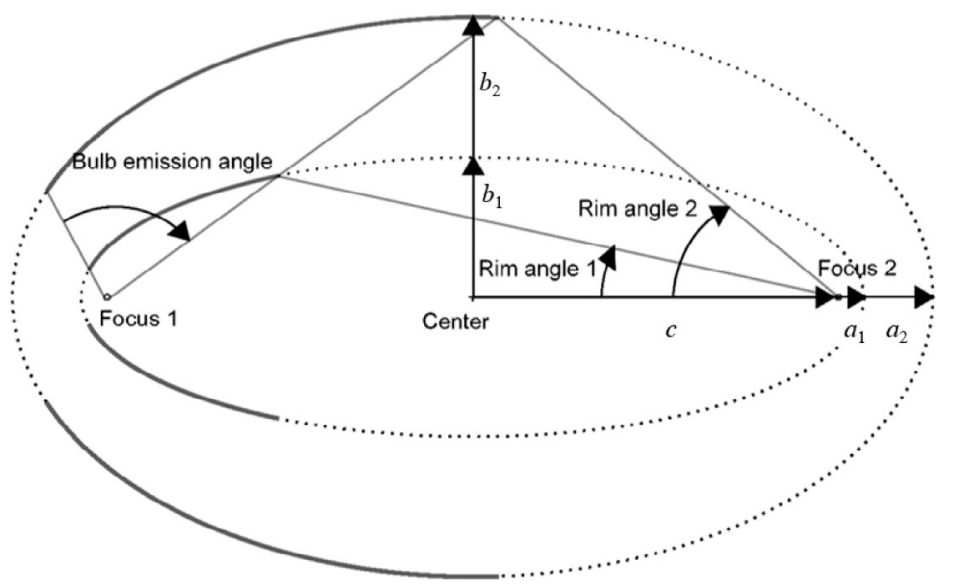

b)

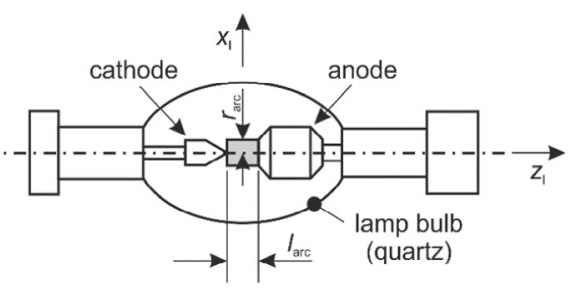

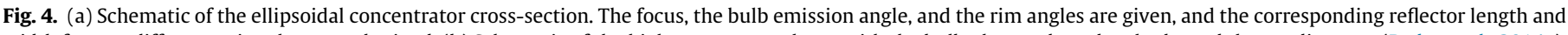

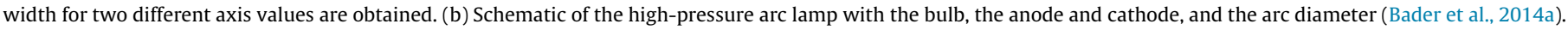
(Reprinted with permission from ASME.) 

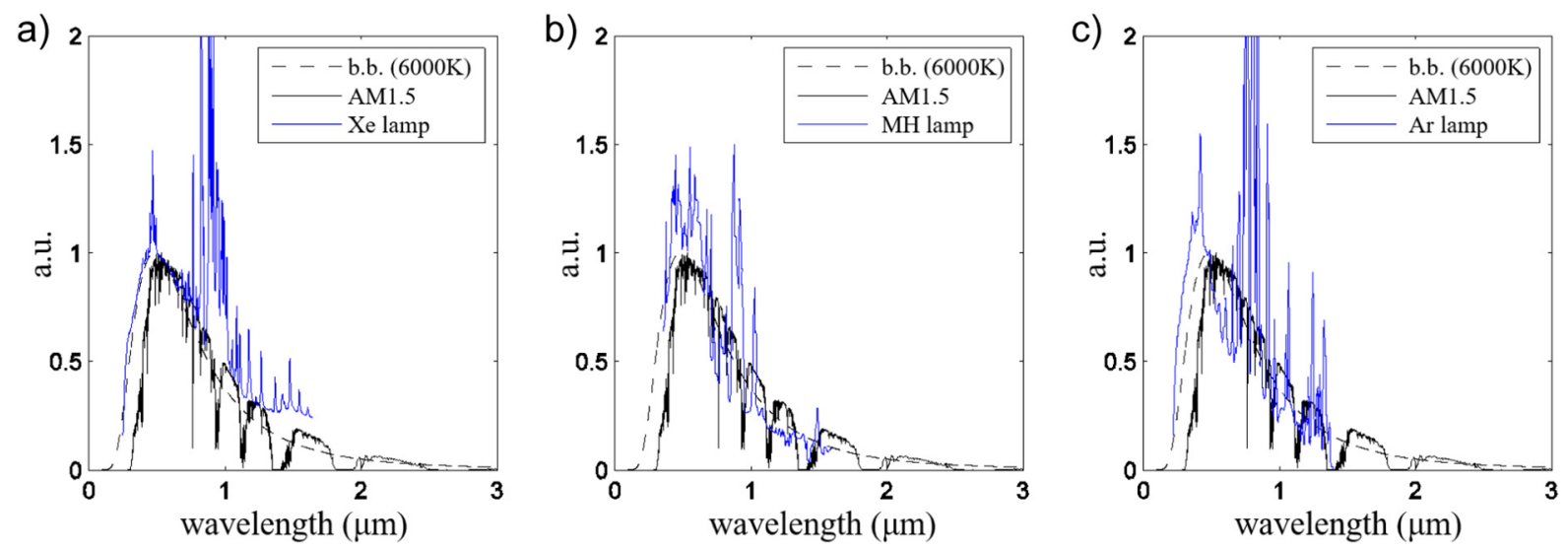

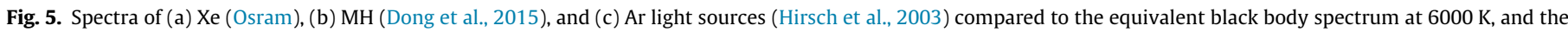
AM1.5D reference spectrum (Bader et al., 2016).

$\left\{\begin{array}{l}x=\frac{2 f \sin \left(\varphi-\theta_{\text {in }}\right)}{1-\cos \varphi}-r_{\text {out }} \\ y=\frac{2 f \cos \left(\varphi-\theta_{\text {in }}\right)}{1-\cos \varphi}\end{array}\right.$,

$r_{\text {out }}=r_{\text {in }} \sin \theta_{\text {in }}$,

$f=r_{\text {out }}\left(1+\sin \theta_{\text {in }}\right)$,

$2 \theta_{\text {in }} \leqslant \varphi \leqslant \frac{\pi}{2}+\theta_{\text {in }}$.

For given $r_{\text {in }}$ and $\theta_{\text {in }}$, which are the acceptance parameters, a CPC allows for every incoming ray with $\theta \leq \theta_{\text {in }}$ to be reflected once toward the outlet of the CPC ("below" the focal point, i.e. out of the $\mathrm{CPC})$, while other rays $\left(\theta>\theta_{\text {in }}\right)$ are reflected back out from the inlet ("above" the focal point, on the CPC surface). The maximum concentration reached for such system depends on the inlet and outlet acceptance angles,

$C=\frac{\sin ^{2} \theta_{\text {out }}}{\sin ^{2} \theta_{\text {in }}}$

CPCs can be two-dimensional translations, or threedimensional revolutions of this parabola. It is noteworthy to point out that the concentration is maximized when $\theta_{\text {out }}$ is equal to $\pi / 2$, i.e. the outlet rays are fully diverging. As a result, such optical systems are generally used closely coupled to the receiver, which is preferably a cavity type receiver. The CPC can even be directly implemented as part of the receiver, which ensures a perfect light transmission but can result in complex gas products management (Müller et al., 2006). The use of arrays of planar mirrors instead of the CPC is an approach to limit the complexity of manufacturing large CPCs (Yogev, 1998). In this particular design, the revolution paraboloid was approached by a 6 sided shape, which offers similar optical efficiency as a continuous CPC and allows to imbricate closely the CPCs.

\subsection{Receivers}

The concentrated solar radiation is provided to a receiver, which has to be designed as to efficiently capture and absorbed the radiation, with its given spatial and angular distribution. As stated, high flux radiation (with concentrations above 100) is an excellent source for high temperature processes. To limit radiative and convective losses, this heat is preferably received and contained in an insulated cavity, with only a small aperture for the radiative flux to enter. Such a configuration limits the re-radiation losses to the minimum and helps increasing the absorbance by "trapping" the light. This design approach follows the idea of a blackbody receiver. This device is called the receiver. The receiver is not part of the HFOS. However, its design highly depends on the characteristics of the concentrated solar radiation.

Two possibilities exist for ultimately delivering the high flux to the reactants: (i) its direct irradiation, or (ii) its resorting to an intermediate material which absorbs the radiative flux and transfers it via conduction and convection to a different chamber, radiatively separated from the incident flux. The first solutions brings forth the concept of a receiver-reactor, where the high flux is converted into heat and directly delivered to the reactants, which are generally used as the absorbing material. The second requires the decoupling of the flux conversion into heat and its further use in a reaction. The choice depends mainly on the type of reaction: direct irradiation requires that the reactant absorbs correctly in the source spectrum. Most gases and some liquids are not good absorbers, requiring an intermediate absorber that has good flux absorbance and heat conductance. Another important criterion is the need for containment. Indeed, low- or high-pressure reactions, or the production of reactive gaseous products can render it impossible to couple the flux absorber and the chemical reactor functionality of the device.

\subsubsection{Coupled receiver-reactors}

In this configuration, the reactants are generally directly heated as part of the absorbing material. Absorbance can be realized on a surface, or through a volume. Surface absorption is generally considered as allowing the highest temperatures with limited material constraints. Indeed, the highest temperature is obtained on the reactant itself, not on the construction materials of the cavity. Volumetric absorption increases the penetration of the flux into the reactant, reducing the temperature gradient through the reactant and allowing the heat to penetrate deeper for a more homogeneous heating. If the reactant is a powder, surface reaction is obtained by forming pellets which are fed to the hot cavity, or by lining the cavity inner surface with the powder (even dispersion can be obtained by rotation) (Abanades et al., 2007; Koepf et al., 2016; Levêque and Abanades, 2013; Möller and Palumbo, 2001; Alonso et al., 2013). This approach is generally satisfactory for reactions with consumption of the reactant. Powder can be used also for volumetric absorption. It is realized by circulating the powder in a cyclone or in a fluidized bed (Steinfeld, May 2005; Gokon et al., 2008). This approach is favored in the case of gas-solid reactions where the particles are not consumed (e.g. catalyzed reactions). For bulk reactants, the use of porous absorbers is preferred for the same reasons (Fend et al., 2004). Advances in ceramic foam production allow 
Table 2

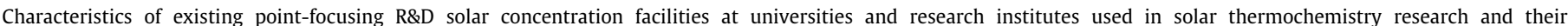
characteristics.

\begin{tabular}{|c|c|c|c|c|c|c|c|c|c|}
\hline Name, Location & $\begin{array}{l}\text { First reference/ } \\
\text { Inauguration }\end{array}$ & Technology & $\begin{array}{l}\text { Reflection } \\
\text { stages }\end{array}$ & $\begin{array}{l}\text { Number of } \\
\text { mirrors }\end{array}$ & $\begin{array}{l}\text { Total size of } \\
\text { collectors }\end{array}$ & $\begin{array}{l}\text { Reflector } \\
\text { shape }\end{array}$ & $\begin{array}{l}\text { Peak } \\
\text { concentration }\end{array}$ & $\begin{array}{l}\text { Radiative } \\
\text { power (kW) }\end{array}$ & Source \\
\hline CSIRO, Australia & - & $\begin{array}{l}\text { Solar } \\
\text { furnace }\end{array}$ & 2 & 1 & - & - & - & - & - \\
\hline CAS, China & 2013 & Multi-dish & 1 & 1 & - & Parabolic & - & 10 & Liao et al. (2013), Peiyao et al. (2007) \\
\hline $\begin{array}{c}\text { MWSF, PROMES- } \\
\text { CNRS, France }\end{array}$ & 1973 & $\begin{array}{l}\text { Solar } \\
\text { furnace }\end{array}$ & 2 & 63 & $2835 \mathrm{~m}^{2}$ & $\begin{array}{l}\text { Parabolic, } \\
\text { discrete }\end{array}$ & 10,000 & 1000 & Trombe and Vinh (1973) \\
\hline $\begin{array}{l}\text { MSSF, PROMES- } \\
\text { CNRS, France }\end{array}$ & 1975 & $\begin{array}{l}\text { Solar } \\
\text { furnace }\end{array}$ & 2 & 1 & $23 \mathrm{~m}^{2}$ & $\begin{array}{l}\text { Parabolic, } \\
\text { discrete }\end{array}$ & 5000 & 6 & Olalde (2007) \\
\hline $\begin{array}{c}\text { MSSFs, PROMES- } \\
\text { CNRS, France }\end{array}$ & 1980 & $\begin{array}{l}\text { Solar } \\
\text { furnace }\end{array}$ & 2 & 1 & $2 \mathrm{~m}^{2}$ & $\begin{array}{l}\text { Parabolic, } \\
\text { continue }\end{array}$ & 16,000 & $1-2$ & Olalde (2007) \\
\hline $\begin{array}{l}\text { DLR-Köln, } \\
\text { Germany }\end{array}$ & 1996 & $\begin{array}{l}\text { Solar } \\
\text { furnace }\end{array}$ & 2 & 1 & $57 \mathrm{~m}^{2}$ & $\begin{array}{l}\text { Parabolic, } \\
\text { discrete }\end{array}$ & 5200 & 25 & Neumann and Groer (1996) \\
\hline WIS, Israel & 1988 & $\begin{array}{l}\text { Solar } \\
\text { reflector } \\
\text { tower }\end{array}$ & 2 & 64 & $3584 \mathrm{~m}^{2}$ & $\begin{array}{l}\text { Hyperbolic } \\
\text { discrete }\end{array}$ & 4000 & 2500 & Segal (2016) \\
\hline $\begin{array}{l}\text { Miyazaki U, } \\
\text { Japan }\end{array}$ & 2014 & $\begin{array}{l}\text { Solar } \\
\text { reflector } \\
\text { tower }\end{array}$ & 2 & 88 & $176 \mathrm{~m}^{2}$ & $\begin{array}{l}\text { Parabolic, } \\
\text { discrete }\end{array}$ & 500 & 100 & Kodama et al. (2014) \\
\hline $\begin{array}{l}\text { HoSIER, UNAM, } \\
\text { Mexico }\end{array}$ & 2014 & $\begin{array}{l}\text { Solar } \\
\text { furnace }\end{array}$ & 2 & 1 & $81 \mathrm{~m}^{2}$ & $\begin{array}{l}\text { Parabolic, } \\
\text { discrete }\end{array}$ & 12,000 & 30 & Perez-Enciso et al. (2014) \\
\hline $\begin{array}{l}\text { KIER, South } \\
\text { Korea }\end{array}$ & 2014 & $\begin{array}{l}\text { Solar } \\
\text { furnace }\end{array}$ & 2 & 1 & $87 \mathrm{~m}^{2}$ & $\begin{array}{l}\text { Parabolic, } \\
\text { discrete }\end{array}$ & 5050 & 40 & Lee et al. (2014) \\
\hline $\begin{array}{l}\text { SSPS-CRS, PSA- } \\
\text { CIEMAT, Spain }\end{array}$ & 1981 & Solar tower & 1 & 91 & $4995 \mathrm{~m}^{2}$ & - & 2500 & 2700 & Wattiez and Ramos (1985) \\
\hline $\begin{array}{l}\text { SF-60, PSA- } \\
\text { CIEMAT, Spain }\end{array}$ & 1992 & $\begin{array}{l}\text { Solar } \\
\text { furnace }\end{array}$ & 2 & 1 & $120 \mathrm{~m}^{2}$ & $\begin{array}{l}\text { Parabolic, } \\
\text { discrete }\end{array}$ & 3000 & 60 & Povedano and Rodríguez (1992) \\
\hline $\begin{array}{l}\text { SF 40, PSA- } \\
\text { CIEMAT, Spain }\end{array}$ & 2016 & $\begin{array}{l}\text { Solar } \\
\text { furnace }\end{array}$ & 2 & 1 & $100 \mathrm{~m}^{2}$ & $\begin{array}{l}\text { Parabolic, } \\
\text { contin. }\end{array}$ & 7000 & 40 & Rodriguez et al. (2016) \\
\hline $\begin{array}{l}\text { SF 5, PSA- } \\
\text { CIEMAT, Spain }\end{array}$ & 2014 & $\begin{array}{l}\text { Solar } \\
\text { furnace }\end{array}$ & 2 & 1 & $25 \mathrm{~m}^{2}$ & $\begin{array}{l}\text { Parabolic, } \\
\text { discrete }\end{array}$ & 6000 & 5 & Rodríguez et al. (2014) \\
\hline PSI, Switzerland & 1999 & $\begin{array}{l}\text { Solar } \\
\text { furnace }\end{array}$ & 2 & 1 & $120 \mathrm{~m}^{2}$ & $\begin{array}{l}\text { Parabolic, } \\
\text { contin. }\end{array}$ & 5000 & 40 & Haueter et al. (1999) \\
\hline MIST, UAE & 2014 & $\begin{array}{l}\text { Solar } \\
\text { reflector } \\
\text { tower }\end{array}$ & 2 & 33 & $281 \mathrm{~m}^{2}$ & $\begin{array}{l}\text { Hyperbolic } \\
\text { discrete }\end{array}$ & - & 100 & Mokhtar et al. (2014) \\
\hline Uzbekistan & 1981 & $\begin{array}{l}\text { Solar } \\
\text { furnace }\end{array}$ & 2 & 62 & $3023 \mathrm{~m}^{2}$ & $\begin{array}{l}\text { Parabolic, } \\
\text { discrete }\end{array}$ & 10,000 & 1000 & $\begin{array}{l}\text { Unique objects and collections of } \\
\text { Uzbekistan Academy of Sciences }\end{array}$ \\
\hline NREL, USA & 1994 & $\begin{array}{l}\text { Solar } \\
\text { furnace }\end{array}$ & 2 & 1 & $35 \mathrm{~m}^{2}$ & $\begin{array}{l}\text { Parabolic, } \\
\text { discrete, }\end{array}$ & 2500 & 10 & Furler et al. (2014), Laumert (2016) \\
\hline PNNL, USA & 2011 & Dish $^{\mathrm{b}}$ & 1 & 1 & $\sim 17 \mathrm{~m}^{2}$ & $\begin{array}{l}\text { Parabolic, } \\
\text { discrete }\end{array}$ & - & $7.5^{\mathrm{a}}$ & Wegeng (2011) \\
\hline SNL, USA & 1980 & $\begin{array}{l}\text { Solar } \\
\text { furnace }\end{array}$ & 2 & 1 & $95 \mathrm{~m}^{2}$ & $\begin{array}{l}\text { Parabolic, } \\
\text { discrete }\end{array}$ & 5000 & 16 & $\begin{array}{l}\text { Project Profile: National Solar Thermal } \\
\text { Test Facility }\end{array}$ \\
\hline $\begin{array}{l}\text { Valparaiso U, } \\
\text { USA }\end{array}$ & 2014 & $\begin{array}{l}\text { Solar } \\
\text { furnace }\end{array}$ & 2 & 1 & $37 \mathrm{~m}^{2}$ & $\begin{array}{l}\text { Parabolic, } \\
\text { discrete }\end{array}$ & 3000 & 10 & Duncan et al. (2014) \\
\hline
\end{tabular}

a Estimated based on the electrical output of the Stirling engine.

b Infinia dish.

producing tailor-made dual-scale porosities that favor a high penetration depth of the flux via large scale pores, and smaller scale pores leading to high specific surface area for solid-gas interactions (Furler et al., 2014). The main drawback of such an approach is the difficulty to enclose the reaction from ambient air while letting the radiative flux in. The use of a quartz window or dome (for vacuum conditions) is a viable solution, though it increases the complexity of the design and requires additional care in terms of temperature and mechanical stress. The main issue comes from the deposition of particles or smoke on the window, which can absorb light and rapidly heat it to the breaking point. This problem can be contained via a well-designed gas sweeping strategy (Kogan and Kogan, 2002).

\subsubsection{Decoupled receiver and reactors}

The decoupling of the light absorption and the chemical reaction functionality into a separate receiver and reactor chamber allows for individual device optimization. The receiver's sole purpose is to heat the intermediate surface (a tube or a plate), which in turn will heat the reactant through radiation, conduction and/ or convection while containing them. In such a case, it is expected that the cavity itself will have a significantly higher temperature compared to the reactants. This can be an important factor in the choice of the materials of the receiver. Tubes are generally used for circulating reactants, and surface for packed-bed reactants (e.g. Levêque and Abanades, 2014; Wieckert et al., 2007). To enhance the direct absorption of light on a multi-tube configuration, the use of reflecting cavity has been proposed (Haussener et al., 2009).

\section{Numerical modeling of HFOS}

Numerical models are used to ensure that the design choices (e.g. reflector arrangement, size, shape, materials, etc.) allow for reaching the design objectives (e.g. radiative power, radiative flux distribution, and optical efficiency on a given surface area, etc.). It is predicted that the most efficient geometries are numerically designed utilizing multi-objective optimization approaches.

Two approaches can be used to estimate the radiation output of a solar optical system. Convolution methods use as starting point 
Table 3

Characteristics of existing solar simulator facilities at universities and research institutes used in solar thermochemistry research.

\begin{tabular}{|c|c|c|c|c|c|c|c|c|c|c|c|}
\hline Location & $\begin{array}{l}\text { First } \\
\text { literature } \\
\text { reference }\end{array}$ & $\begin{array}{l}\text { Number of } \\
\text { modules }\end{array}$ & $\begin{array}{l}\text { Power } \\
\left(\mathrm{kW}_{\mathrm{e}}\right)\end{array}$ & $\begin{array}{l}\text { Rim } \\
\text { angle } \\
\text { (deg) }\end{array}$ & $\begin{array}{l}\text { Reflector } \\
\text { shape }\end{array}$ & $\begin{array}{l}\text { Lamp } \\
\text { type }\end{array}$ & $\begin{array}{l}\text { Peak flux } \\
\left(\mathrm{MW} \mathrm{m}^{-2}\right)\end{array}$ & $\begin{array}{l}\text { Radiative } \\
\text { power }(\mathrm{kW})\end{array}$ & $\begin{array}{l}\text { Average flux } \\
\left(\mathrm{MW} \mathrm{m}^{-2}\right)\end{array}$ & $\begin{array}{l}\text { Ref. area } \\
\operatorname{dim} .(\mathrm{mm})\end{array}$ & Source \\
\hline LBL & 1991 & 1 & $20(30)$ & $\mathrm{n} / \mathrm{a}$ & Ellipsoid & $\mathrm{Xe}$ & 16 & 3 & 0.6 & $70 \times 70$ & Kuhn and Hunt (1991) \\
\hline ETHZ & 2003 & 1 & 200 & 45 & Ellipse & $\mathrm{Ar}$ & 4.3 & 6.7 & 2.4 & 60 & Hirsch et al. (2003) \\
\hline ETHZ & 2007 & 7 & 42 & 45 & Ellipsoid & $\mathrm{Xe}$ & 6.0 & 10 & 3.2 & 60 & $\begin{array}{l}\text { Petrasch et al. (2007), Steinfeld } \\
\text { (2016) }\end{array}$ \\
\hline DLR & 2014 & 10 & 60 & $\mathrm{n} / \mathrm{a}$ & Ellipsoid & $\mathrm{Xe}$ & $\sim 5.0$ & $\sim 20$ & $>4.5$ & 60 & Dibowski (2014) \\
\hline PSI & 2007 & 10 & 150 & 40.6 & Ellipsoid & $\mathrm{Xe}$ & $>11$ & 20 & 6.8 & 60 & Petrasch et al. (2007) \\
\hline UMN & 2011 & 7 & 45.5 & 37.7 & Ellipsoid & $\mathrm{Xe}$ & 7.9 & 9.2 & $>3.24$ & 60 & Krueger et al. (2013, (2011) \\
\hline Texas A\&M & 2014 & 1 & 7 & $\mathrm{n} / \mathrm{a}$ & Ellipsoid & $\mathrm{Xe}$ & 3.8 & 1.0 & 0.25 & 70 & Sarwar et al. (2014) \\
\hline ANU/EPFL & 2016 & 18 & 45 & 45 & Ellipsoid & $\mathrm{Xe}$ & 21.7 & 8.4 & 3.0 & 60 & Levêque et al. (2016) \\
\hline $\begin{array}{l}\text { Swinburne } \\
\text { UT }\end{array}$ & 2015 & 7 & 42 & 31 & Ellipsoid & $\mathrm{MH}$ & 1.1 & 12 & 0.5 & 175 & Ekman et al. (2015) \\
\hline U Adelaide & 2015 & 7 & 42 & $\mathrm{n} / \mathrm{a}$ & Ellipsoid & $\mathrm{MH}$ & 2.8 & 4.5 & 1.6 & 60 & Dong et al. (2015) \\
\hline KTH & 2016 & 12 & 84 & 45 & $\begin{array}{l}\text { Parabolic } \\
+ \text { Fresnel }\end{array}$ & $\mathrm{Xe}$ & 7.22 & 10.6 & 3.75 & 60 & $\begin{array}{l}\text { Wang et al. (2013), Aichmayer } \\
\text { et al. (2016), Laumert (2016) }\end{array}$ \\
\hline $\begin{array}{r}\text { Georgia } \\
\text { Tech }\end{array}$ & 2015 & 7 & 42 & $\mathrm{n} / \mathrm{a}$ & Ellipsoid & $\mathrm{Xe}$ & 6.8 & 6.1 & 4.9 & 40 & Gill et al. (2015) \\
\hline Niigata U & 2015 & 19 & 133 & $\mathrm{n} / \mathrm{a}$ & Ellipsoid & $\mathrm{Xe}$ & $2^{\mathrm{a}}$ & $\sim 30$ & $\sim 0.95$ & $\sim 200$ & Kodama et al. (2015) \\
\hline $\begin{array}{l}\text { N China Elec. } \\
\text { Power U }\end{array}$ & 2016 & 7 & 70 & $\sim 21$ & Ellipsoid & $\mathrm{Xe}$ & $>4.0$ & 20 & $\mathrm{n} / \mathrm{a}$ & $\mathrm{n} / \mathrm{a}$ & Xu et al. (2016) \\
\hline Sandia NL & 2015 & 4 & 7.2 & $\mathrm{n} / \mathrm{a}$ & Ellipsoid & $\mathrm{MH}$ & 1.2 & 1.58 & 0.56 & 60 & Boubault et al. (2015) \\
\hline Bucknell U & 2012 & 1 & 2.5 & $\mathrm{n} / \mathrm{a}$ & Ellipsoid & $\mathrm{MH}$ & 0.86 & 0.914 & 0.323 & 60 & Siegel (2016) \\
\hline $\begin{array}{l}\text { Sandia NL } \\
\text { (planned) }\end{array}$ & - & 4 & 10 & 25 & Ellipsoid & $\mathrm{MH}$ & 3.12 & 3.26 & 1.15 & 60 & Siegel (2016) \\
\hline DLR & 2017 & 149 & 1043 & $\mathrm{n} / \mathrm{a}$ & $\mathrm{n} / \mathrm{a}$ & $\mathrm{Xe}$ & 11 & 500 & $\mathrm{n} / \mathrm{a}$ & $\mathrm{n} / \mathrm{a}$ & DLR \\
\hline
\end{tabular}

a Estimated based on peak to average ratio of similar 7-lamp based simulators.

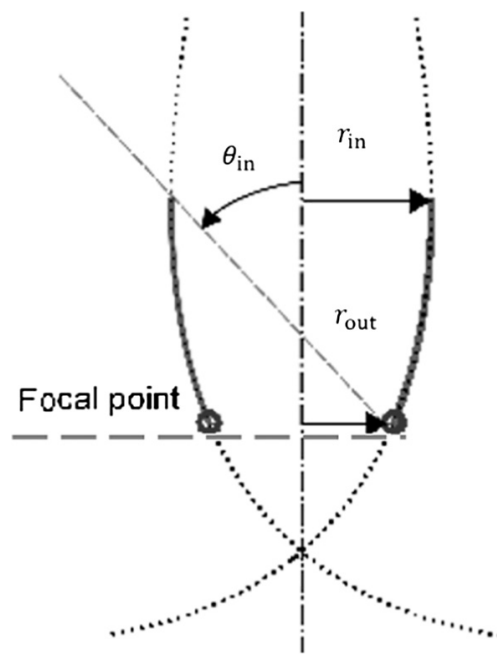

Fig. 6. Schematic of a cross-section of a CPC indicating the inlet and outlet radii, the two focal points of the truncated, tilted parabolas, and the acceptance angle.

the true intensity distribution of the sun, which is then convoluted with the characteristics of the reflecting surfaces (incidence angle, optical losses and imperfections) (Monterreal, 1999). Monte Carlo Ray tracing methods consist of generating photon-like particles (or energy bundles) and following them as they are reflected toward the receiver. Introductions to the Monte Carlo ray tracing methodology can be found for example in Siegel (1971) and Modest (2013). The latter method is considered more precise but requires significantly more computational power as millions of rays need to be generated; the former allows fast calculations at the expense of flexibility. As a result, convolution based methods have been used historically (in codes UHC Pitman and Vant-Hull, 1989, DELSOL (Kistler, 1986), HFLCAL (Schwarzbözl et al., 2011) and for specific applications (e.g. quick comparison of various opti- cal configurations in an optimization code (Augsburger, 2013)). However, the trend shifts to the generalization of Monte Carlo methods resulting from the easy accessibility of highperformance computing. Here, we focus on presenting such Monte Carlo approaches.

Important to both solar concentrators and simulators is the correct description of the optical surface properties, and particularly the surface errors of specular reflectors. For solar simulators, the accurate spectral and directional description of the light source needs to be known. For solar concentrators, the ray tracing model needs to take into account the angular distribution of the incident direct solar radiation (referred to as sunshape model), and errors introduced by sun tracking. If multiple concentrators are used side-by-side, such as in a field of solar parabolic trough or dish concentrators, in addition the effect of mutual shading needs to be taken into account. In heliostat field models, additionally blocking and spillage of radiation needs to be taken into account. Finally, if the radiation path-length is long compared to the extinction length of the atmosphere, atmospheric extinction of the radiation needs to be accounted for.

\subsection{Monte Carlo ray tracing codes}

In recent years, a variety of Monte Carlo ray-tracing codes have been developed and used to model optical systems for concentrating solar energy applications. For specific applications, such as modeling of novel types of solar concentrators or simulators, inhouse algorithms are usually developed and used, which can be tailored to the problem at hand. Examples include solar concentrators with uncommon surface shapes and solar simulators with specific lamp characteristics (Petrasch et al., 2007; Gill et al., 2015; Yabe et al., 2008; Bader et al., 2014a; Zanganeh et al., 2012). Some of these codes have been released as open-source software or algorithm, such as CUtrace, VeGas, Tracer, and Tonatiuh (Rowe et al., 2015; Petrasch, 2010; Tracer; Tonatiuh). To model more generic and larger scale problems, such as heliostat fields and solar furnaces, mainly three free simulation codes have 
been developed as multi-purpose tools: Tonatiuh, developed at CENER, SolTrace, developed at NREL, initially released in 2003 and updated in 2013, and SolFast, developed at CNRS (Blanco et al., 2005; Wendelin et al., 2013; Roccia et al., 2012). In addition, a number of commercial software packages exists that can be used to model solar optical systems. Examples are TracePro, FRED optical software (Ekman et al., 2015; Dong et al., 2015), and LightTools. Differences among the existing Monte Carlo ray tracing simulation packages include the programming language, the use of parallelization, the available surface geometries, light source (including sunshape) models, surface error and optical property models, the user interface, the post-processing capabilities, and the level of technical support. The field is dynamic, and recent advances in Monte Carlo ray tracing modeling are being presently evaluated for solar concentrated power applications (Delatorre et al., 2014). Comparisons among some of the simulation codes mentioned above have been conducted in the last years (Roccia et al., 2012; Garcia et al., 2008). A recent overview of available optical simulation tools for solar concentrating systems is provided in Li et al. (2016).

\subsection{Modeling of solar concentrators}

Reflector surfaces are either modeled as specular or specular/ diffuse. Reflector imperfections, e.g. due to manufacturing tolerances and distortions caused by gravity and temperature variations, are modelled as randomly distributed over the reflector surface. The surface error can be introduced by modifying the analytically calculated surface normal vector on the reflector. The modification can be described with polar coordinates with the azimuthal angle assumed to be uniformly distributed between 0 and $2 \pi$, while for the polar angle either a Gaussian probability density function or a Rayleigh probability density function is used (Bader et al., 2014a; Krueger, 2012; Petrasch, 2010; Johnston, 1995). The incidence direction of direct solar radiation is modeled as either a uniformly emitting disk subtending a cone-half angle of $4.65 \mathrm{mrad}$, a disk with a Gaussian distributed radial brightness profile, or by using a sunshape model developed using experimental data of the brightness distribution of the sun as observed on earth (Li et al., 2016; Vittitoe and Biggs, 1981; Rabl and Bendt, 1982; Buie and Monger, 2004). Using the most detailed models available can result in the accurate prediction of measured radiative flux data with Monte Carlo ray tracing models.

\subsection{Modelling of solar simulators}

A particular issue in solar simulator models is the light source. High-flux simulators use ellipsoidal reflectors to image the light source, a short-arc discharge lamp, onto a target surface. Hence, the size and brightness distribution of the light source strongly influences the achievable radiation concentration at the focus. Accurate modeling of this optical system requires an accurate model of the light source. Different lamp models have been used to describe the origin and direction of the light emitted by the lamps. The spatial emission distribution inside the lamp has been modelled as a uniformly emitting cylindrical volume, conical or spherical surface, or combination of multiple spherical and cylindrical surfaces (Dong et al., 2015; Levêque et al., 2016). Due to the strongly non-uniform brightness distribution in actual solar simulator lamps, these models tend to result in an underprediction of the peak flux and an over-prediction of the radiative power incident on the target surface. The directional emission distribution of the lamp is either modelled as isotropic or by using measured data (Petrasch et al., 2007; Levêque et al., 2016; Bader et al., 2014a; Krueger et al., 2011). Using the actual angular emission distribution of the lamp allows to design a reflector that inter- cepts nearly all radiation emitted by the lamp and leads to a better prediction of the lamp-to-target radiation transfer efficiency. A model based on the measured brightness and directional distributions of xenon short-arc lamps, with a fitted exponential decay function for the lamp's radial brightness profile, has recently been shown to result in good agreement between measured and simulated radiative flux and power distributions at the focal plane of a $45 \mathrm{~kW}_{\mathrm{el}}$ multi-source high-flux solar simulator (Levêque et al., 2016). Accurate modeling of the spatial emission distribution inside the lamp of high-flux solar simulators is currently subject of ongoing research.

\section{Engineering aspects}

HFOS require a careful consideration of engineering aspects early in the design to ensure the feasibility and success of an implementation project.

\subsection{Reflecting materials}

Mirrors and reflectors use either silver or aluminum as the reflecting surface material. Aluminum has a reflectance between 88 and $96 \%$ over the whole solar spectrum while silver has lower values than aluminum in the near-IR and higher values than aluminum above a wavelength of $1.7 \mu \mathrm{m}$. Silver is prone to oxidation with a loss of specularity, so it has to be protected by a glass layer (typical back-coated silver mirror). Aluminum oxidation has less impact on its reflectivity, but its surface is more prone to mechanical damages (scratches). Aluminum reflectors are cheaper, both due to the used base material and the manufacturing. In both cases, dielectric coatings can be applied to further enhance the reflectivity of a given part of the spectrum, especially to enhance the IR reflectivity of silver mirrors (Butel et al., 2011). Most setups use flat silver mirrors for heliostats and discrete parabolas. It is expected that large scale installations and the economy of scale would help reducing the cost of these reflectors as the mass of used silver is minimal. For continuous parabolas, metallized stretched films have been demonstrated and exist as commercial products (3 M Solar mirror film, ReflecTech ${ }^{\circledR}$ mirror film, etc). Such films are generally stretched and held on its supporting shape by means of a vacuum (Haueter et al., 1999).

\subsection{Solar concentrators}

The most critical step in a solar concentrator facility lies in the collection of the light, i.e. in the heliostat, heliostat field or dish design and performance. In central receiver solar systems in particular, the main cost and design challenge comes from the heliostat field. Each heliostat has to be built taking into account the local topography and shadowing effects to follow the ideally simulated field. The choices made for the single heliostat have a decisive impact on the overall cost effectiveness of the field, and on the quality of the concentrated flux. An extensive review of the state of the art, comprising a description of the components of a heliostat and economic considerations, can be found in Téllez et al. (2014).

Solar concentrators require a reliable sun-tracking system. This implies that the first reflector(s) (i.e. the heliostat, the heliostat field or the parabola), generally outdoors, need to be motorized along two axes and instrumented, and correctly protected. Tracking can be easily achieved using a PV cell (or an array of) which will produce at its maximum when facing normally the sun. A second possibility is to program the positioning of the reflector based on ephemerides. A hybrid approach is proved to be efficient: the heliostat automatically follows the programmed sun position in 
Table 4

Characteristics of existing point-focusing demonstrator and commercial plants operating at conditions relevant to solar thermochemistry (CPS World, NREL).

\begin{tabular}{|c|c|c|c|c|c|c|c|c|}
\hline Name, Location & $\begin{array}{l}\text { First reference/ } \\
\text { Inauguration }\end{array}$ & Technology & $\begin{array}{l}\text { Reflection } \\
\text { stages }\end{array}$ & $\begin{array}{l}\text { Number of } \\
\text { mirrors }\end{array}$ & $\begin{array}{l}\text { Total size of } \\
\text { collectors }\end{array}$ & Reflector shape & $\begin{array}{l}\text { Peak } \\
\text { concentration }\end{array}$ & $\begin{array}{l}\text { Radiative power } \\
(\mathrm{MW})^{\mathrm{a}}\end{array}$ \\
\hline $\begin{array}{l}\text { Jemalong tower, } \\
\text { Australia }\end{array}$ & 2016 & Solar tower & 1 & 3500 & $15,000 \mathrm{~m}^{2}$ & - & - & 5.5 \\
\hline $\begin{array}{l}\text { Lake Cargelligo, } \\
\text { Australia }\end{array}$ & 2012 & Solar tower & 1 & 620 & $6080 \mathrm{~m}^{2}$ & - & - & 15 \\
\hline SunDrop, Australia & 2016 & Solar tower & 1 & 23,712 & $51,505 \mathrm{~m}^{2}$ & - & - & 7.5 \\
\hline Atacama, Chile & 2018 & Solar tower & 1 & 10,600 & $1,484,000 \mathrm{~m}^{2}$ & - & - & 550 \\
\hline SunCan, China & 2016 & Solar tower & 1 & 1525 & $175,375 \mathrm{~m}^{2}$ & - & - & 50 \\
\hline Supcon, China & 2017 & Solar tower & 1 & 217,440 & $434,880 \mathrm{~m}^{2}$ & - & - & 250 \\
\hline ACME tower, India & 2011 & Solar tower & 1 & 14,280 & $16,222 \mathrm{~m}^{2}$ & - & - & 12.5 \\
\hline Ashalim Pilot B, Israel & 2017 & Solar tower & 1 & 50,600 & $1,052,480 \mathrm{~m}^{2}$ & - & - & 605 \\
\hline $\begin{array}{l}\text { Khi Solar 1, South } \\
\text { Africa }\end{array}$ & 2016 & Solar tower & 1 & 4120 & $576,800 \mathrm{~m}^{2}$ & - & - & 250 \\
\hline PS10, Spain & 2007 & Solar tower & 1 & 624 & $75,000 \mathrm{~m}^{2}$ & - & - & 55 \\
\hline PS20, Spain & 2009 & Solar tower & 1 & 1255 & $150,000 \mathrm{~m}^{2}$ & - & - & 100 \\
\hline Gemasolar, Spain & 2011 & Solar tower & 1 & 2650 & $304,750 \mathrm{~m}^{2}$ & - & - & 100 \\
\hline Mersin tower, Turkey & 2012 & Solar tower & 1 & 510 & - & - & - & 5 \\
\hline Crescent Dunes, USA & 2015 & Solar tower & 1 & 10,347 & $1,197,148 \mathrm{~m}^{2}$ & - & - & 550 \\
\hline Ivanpah, USA & 2014 & Solar tower & 1 & 173,500 & $2,600,000 \mathrm{~m}^{2}$ & - & - & 1960 \\
\hline Sierra Sun Tower, USA & 2009 & Solar tower & 1 & 24,360 & $27,670 \mathrm{~m}^{2}$ & - & - & 25 \\
\hline Maricopa Solar, Dish & 2010 & Dish & 1 & 60 & - & $\begin{array}{l}\text { Parabolic, } \\
\text { discrete }\end{array}$ & - & 7.5 \\
\hline $\begin{array}{l}\text { Tooele Army Depot, } \\
\text { USA }\end{array}$ & 2013 & Dish & 1 & 429 & $15,015 \mathrm{~m}^{2}$ & $\begin{array}{l}\text { Parabolic, } \\
\text { discrete }\end{array}$ & - & 7.5 \\
\hline
\end{tabular}

a Based on electrical power output with $20 \%$ efficiency.

cloudy conditions, and a direct tracking system increases the accuracy when the sun shines. For optical systems comprising various heliostats, in some cases a differential pointing strategy can be used to homogenize the irradiation, or mitigate transient effects (Augsburger, 2013; Salomé et al., 2013). This type of fine tuning of each heliostat's aim is efficient but requires an evolved tracking system, including a real time position feedback from each heliostat.

\subsection{Solar simulators}

The operational voltage input to Xe arc lamps typically is in the range of 18 to $35 \mathrm{~V}$ DC. MH lamps use higher voltages up to $380 \mathrm{~V}$ (Rowe et al., 2015). The radiative power output of the lamps can be adjusted within limits by varying the current input to the lamp. For ignition, the lamps require a short-time HF-ignition voltage of several $\mathrm{kV}$. This is supplied individually to each lamp by switch-mode power supplies and additional igniter devices that provide the high-voltage burst (Bader et al., 2014b). During operation, the lamps typically need to be actively cooled for example with an air fan.

The power-supply units can be operated manually for maintenance work, e.g. during the replacement or adjustment of the lamps. For regular operation, all units should be remotely operated via a control network. This also includes the transmission of realtime data, e.g. the actual DC current, electric power, and status monitoring of the switch-mode power supplies and related equipment like cooling fans (Bader et al., 2014b).

Radiation modules can be mounted with commercial assembly technology such as Bosch Rexroth profile frames. The lamp and reflector positions and orientations should be adjustable, in order to fine-tune the focus of each radiation module individually (Bader et al., 2014a).

\section{Experimental characterization}

Three main approaches for the experimental characterization of the radiative output of solar optical systems have been described in literature. The first consists of the direct measurement of the radia- tive flux using one or an array of flux sensors, which can be moved (rotated), directly providing an absolute fluxmap without the need of further processing of data or calibration (Villasmil et al., 2013). Such an approach is time consuming, and the spatial resolution is limited by the size of the sensor at the minimum and by the positioning accuracy and range of the sensor. The second approach is the most widely used: a cooled Lambertian (diffuse) target is placed at the focus of the setup, and greyscale (GS) pictures of it are recorded with a CCD or CMOS camera while the target is illuminated. Then, the flux is measured with a flux sensor at selected positions within the target area and compared to the GS values recorded at the same points, and a calibration curve is established between the two quantities. The pictures are finally converted to flux maps using this calibration (Agrafiotis et al., 2014; Licht, 2009; Gálvez et al., 2007; McKone et al., 2013; Müller et al., 2006; Yogev, 1998). The Lambertian surface, obtained by alumina sputtering or magnesium oxide smoking, ensures that the light impacting it is reflected equally in all directions, so the image is the "same" when seen from any direction. The CCD camera has the advantage of providing GS values directly proportional to the light impacting each pixel, resulting in a linear relation to the flux, but the scale is limited in range and accuracy. As a result, measuring precisely different ranges of flux can prove to be difficult. To circumvent this limitation, filters have been used by most research groups: neutral density filters are added in front of the camera as the flux increases, with each filter configuration requiring a different calibration. More recently, the linearity of the CCD camera response to the "amount" of light impacting the chip has been demonstrated to provide an easier and accurate correction method. By dividing the GS values by the exposure time, it has been shown that the resulting values are independent of the exposure time, reducing it to a flux-like quantity. Thus, a calibration can be established regardless of the exposure time, which can be adapted independently to the flux range to ensure a maximum meaning of the CCD pictures (Levêque et al., 2016). In addition, a spatial correction may be required to compensate for non-normal alignment of the camera with the target plane (Sarwar et al., 2014; Krueger, 2012). Different types of flux sensors have been successfully used: Kendall radiometers, Gardon-type gauges, and calorimeters. Suita- 


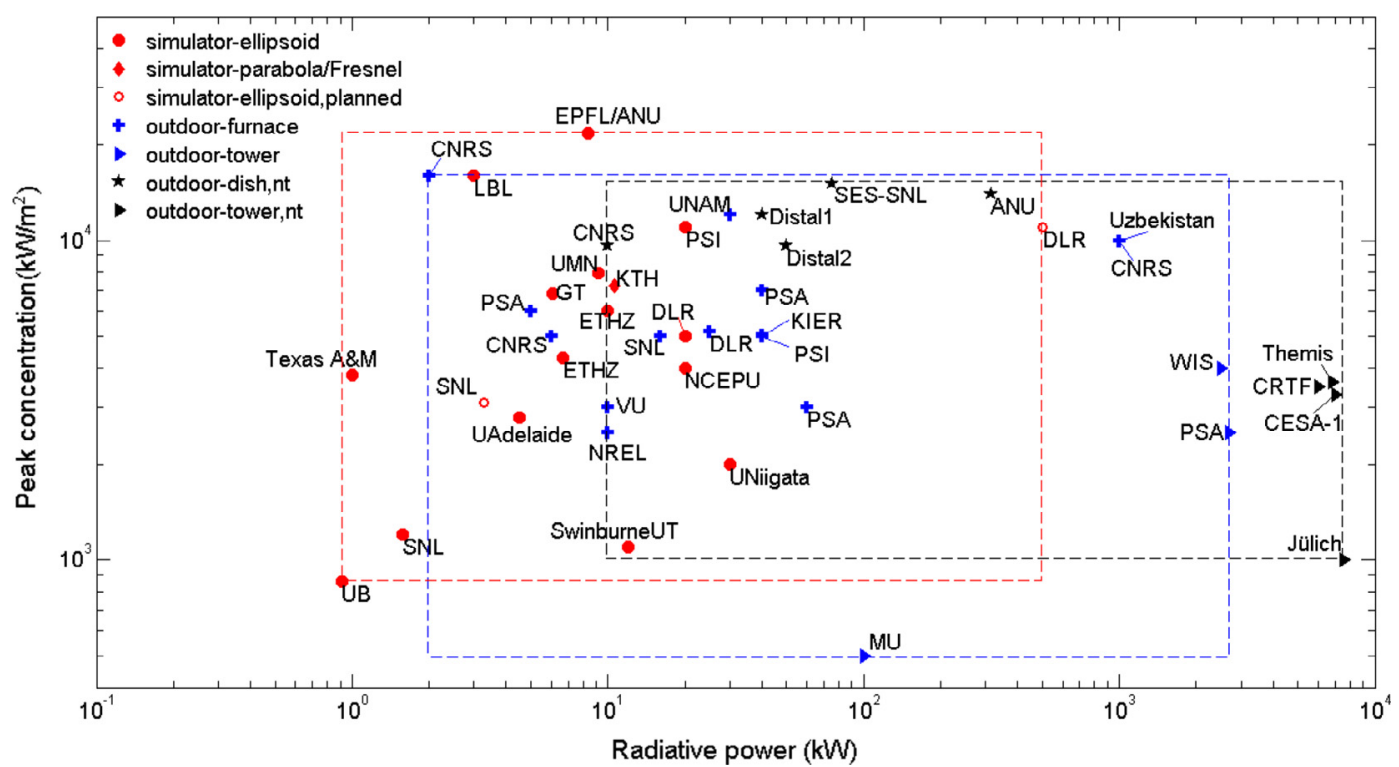

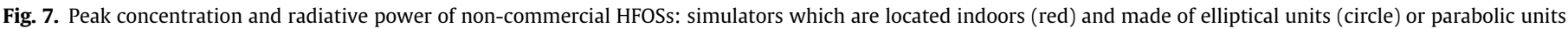

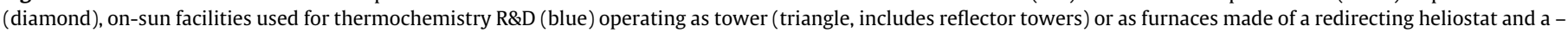

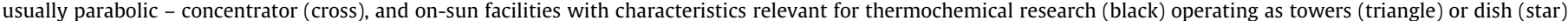

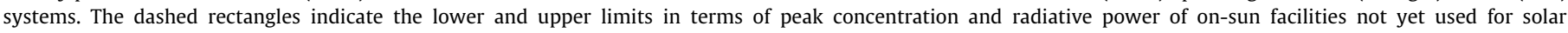

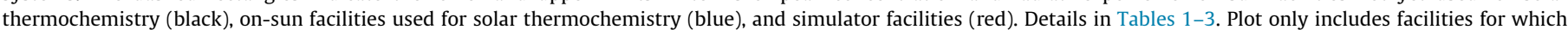

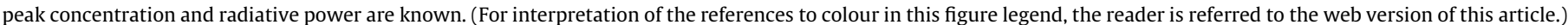

ble Kendall radiometers and calorimeters are difficult to find commercially. Calorimeters have been custom-built in-house. Both have the advantage of providing an absolute value of the flux. Gardon-type gauges are available commercially but require a calibration adapted to the source. A test campaign was conducted to compare and unify the results obtained with the different types of flux sensors and calibrations used by the European solar laboratories, concluding in an agreement within $10 \%$ of the different types of devices (Guillot et al., 2014). Finally, a third measurement approach used for lower concentration devices has the potential to be used for high fluxes too. It consists of the transient measurement of the temperature of a surface heated by the concentrated flux with an infrared camera. If the target's physical properties (absorptivity, emissivity, density, heat capacity) are known, and a precise direct thermal model established (i.e. which gives the temperature evolution of the surface as a function of the incoming flux), it can be inversed to determine the incoming flux on the surface (Pozzobon and Salvador, 2015). It presents the advantage of simplifying the setup, since no special target or flux sensors are needed, while IR cameras are often available in laboratories working with high temperatures. This method has been used for medium fluxes using a painted steel target. It could be extended to higher fluxes using a target resisting higher temperature, or used as is for lower fluxes (e.g. one lamp at a time for a solar simulator, or with sunset light for a solar concentrator) and scaled up.

\section{Inventory of existing HFOSs}

Table 1 provides a summary of the characteristics of on-sun HFOSs utilizing point-focusing concentration and consequently providing concentrations and temperatures interesting to solar thermochemical research. Table 2 provides a summary of the characteristics of on-sun HFOSs that have been used for solar thermochemical research. Table 3 provides a summary of the characteristics of indoor solar simulators that have been used for solar thermochemical research. Table 4 finally provides a summary of demonstrator and commercial HFOSs utilizing point-focusing

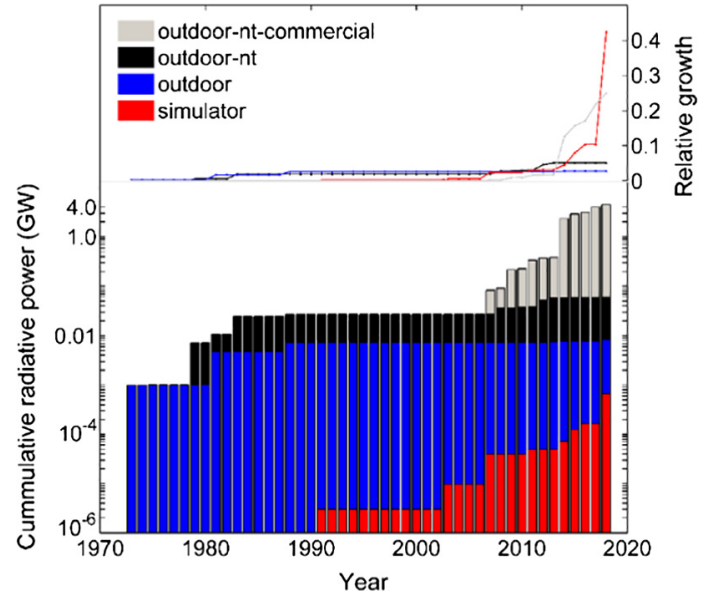

Fig. 8. Cumulative growth of installed radiative power of point-focusing HFOSs, composed of R\&D facilities: simulators (red), on-sun facilities used for thermochemistry (blue), and on-sun facilities with the capability to be used for thermochemistry (black, nt: non-thermochemical); and of commercial facilities with the capability to be used for thermochemistry (grey, nt: non-thermochemical). The relative growth (normalized by the total capacity of its category) indicates a strong growth for simulator installation and commercial point-focusing facilities (currently used for power generation). (For interpretation of the references to colour in this figure legend, the reader is referred to the web version of this article.)

concentration and consequently providing concentrations and temperatures interesting to solar thermochemical research.

The direct comparison in terms of peak concentration and radiative power of research and development level HFOSs is shown in Fig. 7. It is apparent that simulators have provided the largest peak concentrations at intermediate scales, while on-sun facilities usually operate at larger radiative power scales. This is especially true for HFOSs which have - up to now - not been used in solar thermochemistry research. No clear trend towards larger peak concentrations or power in recent years was observed. For simulators however, while there seems to be a general interest in low-cost 
and simple facilities. The recent EPFL/ANU simulator showed the highest achieved peak fluxes and the newly planned DLR simulator will push the boundary with respect to power scale.

Fig. 8 represents the data tabulated in Tables $1-4$ in chronological order. Specifically, the cumulative installed radiative power, and the relative growth of the four groups (solar simulators, noncommercial on-sun systems used for thermochemistry, noncommercial on-sun systems not yet used for thermochemistry, commercial on-sun systems not yet used for thermochemistry) is shown. It is clearly visible that HFOSs picked up some momentum for commercial implementation, even though these implementations aim at solar power production. However, one could argue that a capacity of close to $4 \mathrm{GW}$ radiative power is readily available, exhibiting the right characteristics for solar thermochemistry, and - assuming the solar radiation is converted into hydrogen at a solar-to-fuel efficiency of 5\% - 45,000 tons of hydrogen could readily be produced in a year (corresponding to $0.1 \%$ of the global yearly hydrogen).

\section{Conclusions}

In this study, we have reviewed basic concepts associated with the characterization and design of high-flux optical systems. We provided a short introduction into solar thermochemistry and the relevant temperature conditions for interesting solar thermochemical reactions. We provided the basics and design guidance for concentrating optics, discussed basic HFOS designs, discussed the important component characteristics (artificial or real light source characteristics, and surface characteristics), and provided an overview of the modeling and measurement methods used to quantify the performance of the HFOSs. Finally, we provide an exhaustive list of point-focusing HFOSs (on-sun and simulators) used in or relevant for solar thermochemistry. This data shows that HFOSs for solar thermochemistry have picked up momentum and a variety of projects are under way which aim at building HFOSs with unprecedented peak concentration and radiative power, providing experimental facilities to test, develop, and optimize scaled receivers and reactors for competitive solar thermochemical processes.

\section{References}

Abanades, S., Charvin, P., Flamant, G., 2007. Design and simulation of a solar chemical reactor for the thermal reduction of metal oxides: case study of zinc oxide dissociation. Chem. Eng. Sci. 62 (22), 6323-6333.

Agrafiotis, C., von Storch, H., Roeb, M., Sattler, C., 2014. Solar thermal reforming of methane feedstocks for hydrogen and syngas production-a review. Renew. Sustain. Energy Rev. 29, 656-682.

Aichmayer, L., Wang, W., Garrido, J., Laumert, B., 2016. Experimental flux measurement of a high-flux solar simulator using a Lambertian target and a thermopile flux sensor. In: SolarPaces Conference, p. 130001.

Alonso, E., Hutter, C., Romero, M., Steinfeld, A., Gonzalez-Aguilar, J., 2013. Kinetics of Mn2O3 -Mn3O4 and Mn3O4 -MnO redox reactions performed under concentrated thermal radiative flux. Energy Fuels 27 (8), 4884-4890.

Augsburger, G., 2013. Thermo-economic optimisation of large solar tower power plants. École Polytechnique Fédérale de Lausanne.

Bader, R., Lipinski, W., 2017. Solar thermal processing. In: Blanco, M., Ramirez Santigosa, L. (Eds.), Advances in Concentrating Solar Thermal Research and Technology. Woodhead Publishing, pp. 403-447.

Bader, R., Haussener, S., Lipinski, W., 2014a. Optical design of multisource high-flux solar simulators. J. Sol. Energy Eng. 137 (2), 21012.

Bader, R., Schmidt, L., Haussener, S., Lipinski, W., 2014. A 45 kWe multi-source highflux solar simulator. In: Light, Energy and the Environment, OSA Technical Digest (online) (Optical Society of America, 2014b), paper RW4B.4.

Bader, R., Levêque, G., Haussener, S., Lipinski, W., 2016. High-flux solar simulator technology. In: Light, Energy and the Environment, OSA Technical Digest (online) (Optical Society of America, 2016), paper SoM3C.3.

Blanco, M.J., Amieva, J.M., Mancillas, A., 2005. The Tonatiuh Software Development Project: An Open Source Approach to the Simulation of Solar Concentrating Systems, vol. 2005, pp. 157-164.

Bliss, R.W., 1957. Notes on performance design of parabolic solar furnaces. Sol. Energy 1, 22-29.
Boubault, A., Yellowhair, J., Ho, C.K., 2015. Design and characterization of a $7.2 \mathrm{~kW}$ solar simulator. In: Proc. ASME 2015 9th Int. Conf. Energy Sustainability. ES2015-49472.

Buie, D., Monger, A., 2004. The effect of circumsolar radiation on a solar concentrating system. Sol. Energy 76 (1), 181-185.

Burgess, G., Scott, P., Pye, J., 2008. Spherical and asymmetric mirror panels for paraboloidal concentrators. In: 3rd International Solar Energy Society Conference - Asia Pacific Region (ISES-AP-08) Incorporating the 46th ANZSES Conference, pp. 1-9.

Butel, G.P., Coughenour, B.M., Macleod, H.A., Kennedy, C.E., Olbert, B.H., Angel, J.R.P., 2011. Second-surface silvered glass solar mirrors of very high reflectance, p $81080 \mathrm{~L}$.

Chueh, W.C. et al., 2010. High-flux solar-driven thermochemical dissociation of $\mathrm{CO}_{2}$ and $\mathrm{H}_{2} \mathrm{O}$ using nonstoichiometric Ceria. Science 330 (6012), 1797-1801.

Cooper, T., Scheffe, J.R., Galvez, M.E., Jacot, R., Patzke, G., Steinfeld, A., 2015 Lanthanum manganite perovskites with $\mathrm{Ca} / \mathrm{Sr}$ A-site and $\mathrm{Al} \mathrm{B}$-site doping as effective oxygen exchange materials for solar thermochemical fuel production. Energy Technol. 3 (11), 1130-1142.

CSP World, "CSP World map".

Dahl, J.K. et al., 2004. Rapid solar-thermal dissociation of natural gas in an aerosol flow reactor. Energy 29 (5), 715-725.

Delatorre, J. et al., 2014. Monte Carlo advances and concentrated solar applications. Sol. Energy 103 (May), 653-681.

Dibowski, H.-G., 2014. High-Flux Solar Furnace and Xenon-High-Flux Solar Simulator. Available: <http://www.dlr.de/sf/en/desktopdefault.aspx/tabid10953/19318_read-44891/> [Accessed: Jul 29, 2017].

DLR, “DLR." [Online]. Available: <http://www.dlr.de/sf/en/desktopdefault.aspx/ tabid-10436/12676_read-44362/> [Accessed: 05-Aug-2016].

Dong, X., Sun, Z., Nathan, G.J., Ashman, P.J., Gu, D., 2015. Time-resolved spectra of solar simulators employing metal halide and xenon arc lamps. Sol. Energy 115 613-620.

Dong, X., Nathan, G.J., Sun, Z., Gu, D., Ashman, P.J., 2015. Concentric multilayer model of the arc in high intensity discharge lamps for solar simulators with experimental validation. Sol. Energy 122 (Dec), 293-306.

Dumortier, M., Tembhurne, S., Haussener, S., 2015. Holistic design guidelines for solar hydrogen production by photo-electrochemical routes. Energy Environ. Sci. 8 (12), 3614-3628.

Duncan, G.S., Nudehi, S., Palumbo, R., Venstrom, L.J., 014. A High-Flux Solar Furnace for Undergraduate Engineering Education and High-Temperature Thermochemistry Research, p. V001T02A018.

Ekman, B.M., Brooks, G., Akbar Rhamdhani, M., 2015. Development of high flux solar simulators for solar thermal research. Sol. Energy Mater. Sol. Cells 141, 436446.

Fend, T., Hoffschmidt, B., Pitz-Paal, R., Reutter, O., Rietbrock, P., 2004. Porous materials as open volumetric solar receivers: experimental determination of thermophysical and heat transfer properties. Energy 29 (5-6), 823-833.

Fletcher, E.A., Moen, R.L., 1977. Hydrogen-and oxygen from water. Science 197 (4308), 1050-1056.

Furler, P. et al., 2014. Thermochemical $\mathrm{CO}_{2}$ splitting via redox cycling of ceria reticulated foam structures with dual-scale porosities. Phys. Chem. Chem. Phys. 16 (22), 10503.

Gálvez, M., Frei, A., Halmann, M., Steinfeld, A., 2007. Ammonia production via a twostep $\mathrm{Al}_{2} \mathrm{O}_{3} / \mathrm{AlN}$ thermochemical cycle. 2. Kinetic analysis. Ind. Eng. Chem. Res. 46 (7), 2047-2053.

Garcia, P., Ferriere, A., Bezian, J.-J., 2008. Codes for solar flux calculation dedicated to central receiver system applications: A comparative review. Sol. Energy 82 (3), 189-197.

Gill, R., Bush, E., Haueter, P., Loutzenhiser, P., 2015. Characterization of a 6 kW highflux solar simulator with an array of xenon arc lamps capable of concentrations of nearly 5000 suns. Rev. Sci. Instrum. 86 (12).

Gokon, N., Takahashi, S., Yamamoto, H., Kodama, T., 2008. Thermochemical twostep water-splitting reactor with internally circulating fluidized bed for thermal reduction of ferrite particles. Int. J. Hydrog. Energy 33 (9), 2189-2199.

Goody, R., Yung, Y., 1989. Atmospheric Radiation. Oxford Univ. Press, New York, p. 519.

Goswami, D.Y., Kreith, F., Kreider, J.F., Kreith, F., 2000. Principles of Solar Engineering. Taylor \& Francis, Philadelphia, PA.

Gueymard, C.A., 2004. The sun's total and spectral irradiance for solar energy applications and solar radiation models. Sol. Energy 76 (4), 423-453.

Gueymard, C., Myers, D., Emery, K., 2002. Proposed reference irradiance spectra for solar energy systems testing. Sol. Energy 73 (6), 443-467.

Guillot, E., Alxneit, I., Ballestrin, J., Sans, J.L., Willsh, C., 2014. Comparison of 3 heat flux gauges and a water calorimeter for concentrated solar irradiance measurement. Energy Proc. 49, 2090-2099.

Halmann, M., Frei, A., Steinfeld, A., 2007. Carbothermal reduction of alumina: thermochemical equilibrium calculations and experimental investigation. Energy 32 (12), 2420-2427.

Haueter, P., Seitz, T., Steinfeld, A., 1999. A new high-flux solar furnace for hightemperature thermochemical research. J. Sol. Energy Eng. 121 (1), 77.

Haussener, S., Hirsch, D., Perkins, C., Weimer, A., Lewandowski, A., Steinfeld, A. 2009. Modeling of a multitube high-temperature solar thermochemical reactor for hydrogen production. J. Sol. Energy Eng. 131 (2), 24503.

Hirsch, D., Zedtwitz, P.V., Osinga, T., Kinamore, J., Steinfeld, A., 2003. A new 75 kW high-flux solar simulator for high-temperature thermal and thermochemical research. J. Sol. Energy Eng. 125 (1), 117. 
Johnston, G., 1995. On the analysis of surface error distributions on concentrated solar collectors. J. Sol. Energy Eng. 117 (November), 294-296.

Kistler, B.L., 1986. A user's manual for DELSOL3: a computer code for calculating the optical performance and optimal system design for solar thermal central receiver plants. Sandia Natl. Lab. Sandia Rep. No SAND86-8018.

Kodama, T. et al., 2014. Flux measurement of a new beam-down solar concentrating system in miyazaki for demonstration of thermochemical water splitting reactors. Energy Proc. 49, 1990-1998.

Kodama et al., T., 2015. Particles fluidized bed receiver/reactor with a beam-down solar concentrating optics: $30-\mathrm{kW}$ th performance test using a big sunsimulator. In: SolarPaces conference.

Koepf, E., Villasmil, W., Meier, A., 2016. Pilot-scale solar reactor operation and characterization for fuel production via the $\mathrm{Zn} / \mathrm{ZnO}$ thermochemical cycle. Appl. Energy 165 (March), 1004-1023.

Kogan, A., Kogan, M., 2002. The Tornado flow configuration-an effective method for screening of a solar reactor window. J. Sol. Energy Eng. 124 (3), 206.

Krueger, K.R., 2012. Design and Characterization of a Concentrating Solar Simulator, $\mathrm{PhD}$ Thesis, University of Minnesota.

Krueger, K.R., Davidson, J.H., Lipiński, W., 2011. Design of a new 45 kWe high-flux solar simulator for high-temperature solar thermal and thermochemical research. J. Sol. Energy Eng. 133 (1), 11013.

Krueger, K.R., Lipiński, W., Davidson, J.H., 2013. Operational performance of the University of Minnesota 45 kWe high-flux solar simulator. J. Sol. Energy Eng. 135 (4), 44501.

Kubo, S. et al., 2004. A demonstration study on a closed-cycle hydrogen production by the thermochemical water-splitting iodine-sulfur process. Nucl. Eng. Des. 233 (1), 347-354.

Kuhn, P., Hunt, A., 1991. A new solar simulator to study high temperature solid-state reactions with highly concentrated radiation. Sol. Energy Mater. 24, 742-750.

Laumert, B., 2016. Pers. Communciation.

Lee, H. et al., 2014. Optical performance evaluation of a solar furnace by measuring the highly concentrated solar flux. Energy 66 (Mar), 63-69.

Levêque, G., Abanades, S., 2013. Kinetic analysis of high-temperature solid-gas reactions by an inverse method applied to $\mathrm{ZnO}$ and $\mathrm{SnO}_{2}$ solar thermal dissociation. Chem. Eng. J. 217 (February), 139-149.

Levêque, G., Abanades, S., 2014. Design and operation of a solar-driven thermogravimeter for high temperature kinetic analysis of solid-gas thermochemical reactions in controlled atmosphere. Sol. Energy 105 (Jul), 225-235.

Levêque, G., Bader, R., Lipiński, W., Haussener, S., 2016. Experimental and numerica characterization of a new $45 \mathrm{~kW}$ _el multisource high-flux solar simulator. Opt. Express 24 (22), A1360.

Li, L., Coventry, J., Bader, R., Pye, J., Lipiński, W., 2016. Optics of solar central receiver systems: a review. Opt. Exp. 24 (14). A985-A1007.

Liao, B., Guo, L., Lu, Y., Zhang, X., 2013. Solar receiver/reactor for hydrogen production with biomass gasification in supercritical water. Int. J. Hydrog. Energy 38 (29), 13038-13044.

Licht, S., 2009. STEP (solar thermal electrochemical photo) generation of energetic molecules: a solar chemical process to end anthropogenic global warming. J. Phys. Chem. C 113 (36), 16283-16292.

Loutzenhiser, P.G., Stamatiou, A., Villasmil, W., Meier, A., Steinfeld, A., 2011. Concentrated solar energy for thermochemically producing liquid fuels from $\mathrm{CO}_{2}$ and $\mathrm{H}_{2} \mathrm{O}$. JOM J. Miner. Met. Mater. Soc. 63 (1), 32-34.

Lovegrove, K., Burgess, G., Pye, J., 2011. A new $500 \mathrm{~m}^{2}$ paraboloidal dish solar concentrator. Sol. Energy 85 (4), 620-626.

Maag, G., Zanganeh, G., Steinfeld, A., 2009. Solar thermal cracking of methane in a particle-flow reactor for the co-production of hydrogen and carbon. Int. Hydrog. Energy 34 (18), 7676-7685.

Malonzo, C.D., De Smith, R.M., Rudisill, S.G., Petkovich, N.D., Davidson, J.H., Stein, A., 2014. Wood-templated $\mathrm{CeO}_{2}$ as active material for thermochemical $\mathrm{CO}$ production. J. Phys. Chem. C 118 (45), 26172-26181.

McDaniel, A.H. et al., 2013. Sr- and Mn-doped $\mathrm{LaAlO}_{3}-\delta$ for solar thermochemical $\mathrm{H}_{2}$ and $\mathrm{CO}$ production. Energy Environ. Sci. 6 (8), 2424.

McKone, J.R., Lewis, N.S., Gray, H.B., 2013. Will solar-driven water-splitting devices see the light of day? Chem. Mater. 26 (1), 407-414.

Meier, A., Bonaldi, E., Cella, G.M., Lipiński, W., Wuillemin, D., 2006. Solar chemical reactor technology for industrial production of lime. Sol. Energy 80 (10), 1355 1362.

Modest, M.F. 2013. Radiative Heat Transfer. McGraw-Hill, New York.

Mokhtar, M., Meyers, S.A., Armstrong, P.R., Chiesa, M., 2014. Performance of a 100 kWth concentrated solar beam-down optical experiment. J. Sol. Energy Eng. 136 (4), 41007.

Möller, S., Palumbo, R., 2001. Solar thermal decomposition kinetics of $\mathrm{ZnO}$ in the temperature range 1950-2400 K. Chem. Eng. Sci. 56 (15), 4505-4515.

Monterreal, R., 1999. A new computer code for solar concentrating optics simulation. J. Phys. IV 9 (PR3). Pr3-77-Pr3-82 (Mar).

Müller, R., Haeberling, P., Palumbo, R.D., 2006. Further advances toward the development of a direct heating solar thermal chemical reactor for the therma dissociation of $\mathrm{ZnO}(\mathrm{s})$. Sol. Energy 80 (5), 500-511.

Neumann, A., Groer, U., 1996. Experimenting with concentrated sunlight using the DLR solar furnace. Sol. Energy 58 (4-6), 181-190.

NREL, "Concentrating solar power projects".

Olalde, G., 2007. Final report - SOLFACE, CORDIS, Project report.

Osinga, T., Frommherz, U., Steinfeld, A., Wieckert, C., 2004. Experimental Investigation of the Solar Carbothermic Reduction of $\mathrm{ZnO}$ Using a two-cavity solar reactor. J. Sol. Energy Eng. 126 (1), 633.
Osram, Manufacturer Data.

Peiyao, Y., Laishun, Y., Yuhua, L., Qiuya, N., Jianzhong, T., 2008. Development of the experimental bench for a research on solar-dish power genaration. In: Proceedings of ISES World Congress 2007 (Vol. I-Vol. V), pp. 1785-1790.

Perez-Enciso, R et al. 2014. Three-dimensional Analysis of Solar Radiation Distribution at the Focal Zone of the Solar Furnace of IER_UNAM. Energy Proc. 57, 3031-3040.

Petela, R. et al., 2010. Engineering thermodynamics of thermal radiation for solar power utilization. McGraw Hill.

Petrasch, J., 2010. A Free and Open Source Monte Carlo Ray Tracing Program for Concentrating Solar Energy Research, pp. 125-132.

Petrasch, J. 2010. A free and open source Monte Carlo ray tracing program for concentrating solar energy research. In: Proc. ASME 2010 4th Int. Conf. Energy Sustainability, 2010, p. ES2010-90206/1-8.

Petrasch, J. et al., 2007. A Novel 50 kW 11,000 suns high-flux solar simulator based on an array of xenon arc lamps. J. Sol. Energy Eng. 129 (4), 405-411.

Piatkowski, N., Wieckert, C., Weimer, A.W., Steinfeld, A., 2011. Solar-driven gasification of carbonaceous feedstock-a review. Energy Environ. Sci. 4 (1), $73-82$.

Pitman, C.L., Vant-Hull, L.L., 1989. The University of Houston Solar Central Receiver Code System: Concepts, updates, and start-up kits.

Povedano, J.R., Rodríguez, J., 1992. Performance and characterization of the PSA Solar Furnace. Proc. 6th Int Symp. on Solar Thermal Concentrating Technologies, vol. 2, pp. 1421-1430.

Pozzobon, V., Salvador, S., 2015. High heat flux mapping using infrared images processed by inverse methods: an application to solar concentrating systems. Sol. Energy 117, 29-35. Jul.

"Project Profile: National Solar Thermal Test Facility," Office of energy efficiency \& renewable energy [Online]. Available: <http://energy.gov/eere/sunshot/projectprofile-national-solar-thermal-test-facility $>$.

Pye, J., Coventry, J., Venn, F., Zapata, J., Abbasi, E., Asselineau, C-A., Burgess, G., Hughes, G., Logie, W., 2017, Experimental testing of a high-flux cavity receiver. In: AIP Conference Proceedings 1850, pp. 110011-1-8.

Rabl, A., Bendt, P., 1982. Effect of circumsolar radiation on performance of focusing collectors. ASME J. Sol. Energy Eng. 104 (3), 237-250.

Roccia, J.P. et al., 2012. SOLFAST, a ray-tracing Monte-Carlo software for solar concentrating facilities. J. Phys. Conf. Ser. 369 (Jun), 12029.

Rodríguez, J., Cañadas, I., Zarza, E., 2014. PSA vertical axis solar furnace SF5. Energy Proc. 49, 1511-1522.

Rodriguez, J., Cañadas, I., Zarza, E., 2016. New PSA high concentration solar furnace SF40. In: AIP Conference Proceedings, p. 70028.

Romero, M., Steinfeld, A., 2012. Concentrating solar thermal power and thermochemical fuels. Energy Environ. Sci. 5 (11), 9234-9245.

Rowe, S.C. et al., 2015. Worst-case losses from a cylindrical calorimeter for solar simulator calibration. Opt. Express 23 (19), A1309.

Säck, J.-P. et al., 2016. High temperature hydrogen production: design of a 750KW demonstration plant for a two step thermochemical cycle. Sol. Energy 135, 232241.

Salomé, A., Chhel, F., Flamant, G., Ferrière, A., Thiery, F., 2013. Control of the flux distribution on a solar tower receiver using an optimized aiming point strategy: application to THEMIS solar tower. Sol. Energy 94 (Aug.), 352-366.

Sandia National Lab, "Concentrating solar power".

Sarwar, J., Georgakis, G., LaChance, R., Ozalp, N., 2014. Description and characterization of an adjustable flux solar simulator for solar thermal, thermochemical and photovoltaic applications. Sol. Energy 100, 179-194.

Scheffe, J.R., Steinfeld, A., 2014. Oxygen exchange materials for solar thermochemical splitting of $\mathrm{H}_{2} \mathrm{O}$ and $\mathrm{CO}_{2}$ : a review. Mater. Today 17 (7), 341-348.

Schunk, L.O., Haeberling, P., Wepf, S., Wuillemin, D., Meier, A., Steinfeld, A., 2008. A receiver-reactor for the solar thermal dissociation of zinc oxide. J. Sol. Energy Eng. 130 (2), 21009.

Schwarzbözl, P, Pitz-Paal, R, Belhomme, B., Schmitz, M, 2011. Visual-HFLCAL-eine software zur auslegung und optimierung von solarturmsystemen. Dtsch. Zent. Für Luft- Raumfahrt DLR Cologne Ger.

Segal, A., 2016. Solar energy at high temperatures; researches at the Weizmann Institute of Science, Israel; 25 years of success. Renew. Energy Environ. Sustain. 1,1

Siegel, R., 1971. Thermal Radiation Heat Transfer. McGraw-Hill, New York.

Siegel, N., 2016. Pers. Communciation.

Steinfeld, A., 2005. Solar thermochemical production of hydrogen--a review. Sol Energy 78 (5), 603-615.

Steinfeld, A., 2016. Pers. Communciation.

Sturzenegger, M., Nüesch, P., 1999. Efficiency analysis for a manganese-oxide-based thermochemical cycle. Energy 24 (11), 959-970.

Téllez, F. et al., 2014. Survey for a low-cost heliostat development", Deliverable 12.1.

Tembhurne, S., Haussener, S., 2016a. Integrated photo-electrochemical solar fue generators under concentrated irradiation I. 2-D Non-isothermal multi-physics modeling. J. Electrochem. Soc. 163 (10). H988-H998.

Tembhurne, S., Haussener, S., 2016b. Integrated photo-electrochemical solar fuel generators under concentrated irradiation II. Thermal management a crucial design consideration. J. Electrochem. Soc. 163 (10). H999-H1007.

Tonatiuh [Online]. Available: <http://iat-cener.github.io/tonatiuh/> [Accessed: 03August-2017].

Tracer [Online]. Available: <https://github.com/casselineau> [Accessed: 03-August2017]

Trombe, F., Vinh, A.L.P., 1973. Thousand kW solar furnace, built by the National Center of Scientific Research, in Odeillo (France). Sol. Energy 15 (1), 57-61. 
Tzouganatos, N., Wieckert, C., Steinfeld, A., 2016. A packed-bed solar reactor for the carbothermal zinc production-dynamic modelling and experimental validation. AIChE J. 62 (12), 4586-4594.

"Unique objects and collections of Uzbekistan Academy of Sciences." [Online]. Available: <http://www.academy.uz/en/objects/akn.php?ELEMENT_ID = 23> [accessed: 24-Oct-2016].

Villasmil, W., Brkic, M., Wuillemin, D., Meier, A., Steinfeld, A., 2013. Pilot scale demonstration of a 100-kWth solar thermochemical plant for the thermal dissociation of ZnO. J. Sol. Energy Eng. 136 (1), 11017. Nov..

Vittitoe, C.N., Biggs, F., 1981. Six-gaussian representation of the angular-brightness distribution for solar radiation. Sol. Energy 27 (6), 469-490.

Wang, W., Aichmayer, L., Laumert, B., Fransson, T., 2013. Design and validation of a low-cost high-flux solar simulator using Fresnel lens concentrators. Energy Proc. 49, 2221-2230.

Wattiez, P., Ramos, J., 1985. SSPS-CRS Heliostat Performance/History. In: Gretz, J., Strub, A., Palz, W. (Eds.), Thermo-Mechanical Solar Power Plants. Springer, Netherlands, Dordrecht, pp. 92-99.

Wegeng, R., 2011. Development and Demonstration of a Prototype Solar Methane Reforming System for Thermochemical Energy Storage - Including Preliminary Shakedown Testing Results.
Welford, W.T., 2012. High Collection Nonimaging Optics. Elsevier.

Wendelin, T., Dobos, A., Lewandowski, A., 2013. SolTrace: a ray-tracing code for complex solar optical systems. Contract 303, 275-3000.

Wieckert, C. et al., 2007. A $300 \mathrm{~kW}$ solar chemical pilot plant for the carbothermic production of zinc. J. Sol. Energy Eng. 129 (2), 190.

$\mathrm{Xu}$, J. et al., 2016. Design, construction, and characterization of an adjustable $70 \mathrm{~kW}$ high-flux solar simulator. J. Sol. Energy Eng. 138 (4), 41010.

Yabe, T. et al., 2008. $100 \mathrm{~W}$-class solar pumped laser for sustainable magnesiumhydrogen energy cycle. J. Appl. Phys. 104 (8), 83104.

Yadav, D., Banerjee, R., 2016. A review of solar thermochemical processes. Renew. Sustain. Energy Rev. 54, 497-532. Feb.

Yogev, A., 1998. Solar tower reflector systems: a new approach for hightemperature solar plants. Int. J. Hydrog. Energy 23 (4), 239-245. Apr.

Zanganeh, G., Bader, R., Pedretti, A., Pedretti, M., Steinfeld, A., 2012. A solar dish concentrator based on ellipsoidal polyester membrane facets. Sol. Energy 86 (1), 40-47. 